Fisheries Research

March 2015, Volume 163 Pages 69-84

http://dx.doi.org/10.1016/i.fishres.2014.07.006

http://archimer.ifremer.fr/doc/00254/36513/

(c) 2014 Elsevier B.V. All rights reserved.

\title{
An integrated Bayesian modeling approach for the growth of Indian Ocean yellowfin tuna
}

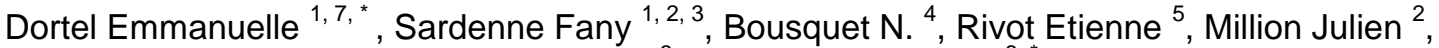 \\ Le Croizier Gael ${ }^{3}$, Chassot Emmanuel ${ }^{6,{ }^{*}}$
}

${ }^{1}$ Inst Rech Dev, IRD Ifremer UM2, UMR EME 212, F-34203 Sete, France.

2 Indian Ocean Tuna Commiss, Victoria, Seychelles.

3 IRD, UMR LEMAR 6539, F-29280 Plouzane, France.

${ }^{4}$ EDF Res \& Dev, Dept Ind Risk Management, F-78401 Chatou, France.

${ }^{5}$ Univ Europeenne Bretagne, Agrocampus Ouest INRA, UMR ESE 0985, F-84215 Rennes, France.

${ }_{7}^{6}$ SFA, IRD Ifremer UM2, UMR EME 212, Victoria, Seychelles.

${ }^{7}$ Ifremer, France

* Corresponding authors : Emmanuelle Dortel, email address : emmanuelle.dortel@ird.fr

Emmanuel Chassot, Tel.: +248 4670307; fax: +248 4224742 ; email address : emmanuel.chassot@ird.fr

\begin{abstract}
:
The Indian Ocean Tuna Tagging Program provided a unique opportunity to collect demographic data on the key commercially targeted tropical tuna species in the Indian Ocean. In this paper, we focused on estimating growth rates for one of these species, yellowfin (Thunnus albacares). Whilst most growth studies only draw on one data source, in this study we use a range of data sources: individual growth rates derived from yellowfin that were tagged and recaptured, direct age estimates obtained through otolith readings, and length-frequency data collected from the purse seine fishery between 2000 and 2010. To combine these data sources, we used an integrated Bayesian model that allowed us to account for the process and measurement errors associated with each data set. Our results indicate that the gradual addition of each data type improved the model's parameter estimations. The Bayesian framework was useful, as it allowed us to account for uncertainties associated with age estimates and to provide additional information on some parameters (e.g., asymptotic length). Our results support the existence of a complex growth pattern for Indian Ocean yellowfin, with two distinct growth phases between the immature and mature life stages. Such complex growth patterns, however, require additional information on absolute age of fish and transition rates between growth stanzas. This type of information is not available from the data. We suggest that bioenergetic models may address this current data gap. This modeling approach explicitly considers the allocation of metabolic energy in tuna and may offer a way to understand the underlying mechanisms that drive the observed growth patterns.
\end{abstract}

Keywords : Indian Ocean yellowfin, Hierarchical Bayesian model, Tagging, Fisheries 


\section{Introduction}

The knowledge of growth variability between individuals is essential to understanding the biology of fish populations, their productivity, and their response to environmental changes and fishing pressure. Indeed, growth rates are an integral part of stock assessments, a process which aims to supply scientific advice on the health of a fishery (Cotter et al., 2004). Consequently, biased growth estimates can affect our understanding of a stock's status and lead to poor fisheries management decisions (Fournier and Archibald, 1982; Kell and Bromley, 2004).

There are three principal data sources available for studying wild fish growth rates: (i) direct aging of a fish of a known size from periodic deposits in hard tissues, (ii) modal progression in length-frequency distributions obtained from commercial fisheries catches or scientific monitoring, and (iii) the increase in fish length over time-at-liberty from mark-recapture experiments. Direct aging data have been widely used to study growth in fish species that consistently deposit growth increments in calcified tissues, such as otoliths (Campana, 2001; Panfili et al., 2002). For example, counting the microstructural features deposited daily in otoliths has been shown to be a useful aging technique for many species of tropical fishes (Pannella, 1971; Green et al., 2009). However, the preparation and analysis of otoliths is time consuming, requires considerable care, and can involve some biases and uncertainties (e.g., miscounting increments can lead to errors in age estimations) (Sardenne et al., this issue). Although considered less accurate than direct aging methods, the analysis of length-frequency data obtained from fisheries catches can provide indirect age estimates for species that exhibit well defined spawning periods (Pauly and Morgan, 1987). In this method, modes (assumed to represent fish cohorts) are identified in the lengthfrequency distributions of catches and their length progression is tracked over time. Finally, mark-recapture data have been widely used since the first tagging experiments were conducted in the early 1950s on tropical tunas in the Pacific 
Ocean. With this method, the change in fish length during the time between release and recovery provides valuable information on how each individual grows over time (Amstrup et al., 2005). However, tagging data do not provide information on the age of a fish and complementary data or expert knowledge are required to anchor the growth curve.

It can be difficult to obtain an overall growth pattern from a single data source, and using all three data sources provides complementary information on the different growth phases experienced over the lifespan of a fish. Although considerable research effort is invested in determining age and growth patterns of fish, to our knowledge, with the notable exception of Eveson et al. (2004), only a few studies have previously attempted to combine the three different data sources into an integrated growth model. Assimilating different growth data sets within a statistical framework is challenging because to do so effectively, we must address: (i) the multiple observation errors in the data, (ii) potential contradictions between data sets, and (iii) the variability in growth among individuals, which is typically modeled by a process error term. The hierarchical Bayesian approach appears particularly well suited for modeling growth because it can integrate several different data sources and allows for stochasticity at multiple levels (Clark, 2005). Bayesian models can draw inferences from large numbers of parameters and latent variables that describe complex relationships. In addition, the Bayesian framework allows for the inclusion of expert judgment and supplementary information.

Yellowfin tuna (Thunnus albacares, Bonnaterre 1788) is an epipelagic species that is widely distributed in the tropical and subtropical waters of the world's major oceans (Fonteneau, 2010). In the Indian Ocean (IO), yellowfin has been commercially exploited since the early 1950s and over the last decade, annual catches have exceeded 350,000 t (Herrera and Pierre, 2010). There is considerable diversity in the fleets that target this species; whilst industrial purse seiners and longliners dominate, small-scale fishing fleets were responsible for more than 
$35 \%$ of total catch estimates in the last decade (Herrera and Pierre, 2010). The management of the IO yellowfin is under the jurisdiction of the Indian Ocean

Tuna Commission (IOTC, www.iotc.org). Currently, their management approach relies on temporal trends in fish abundance and fishing mortality-at-age data derived from a spatially-explicit population model (Langley et al., 2012). The most recent stock assessment from 2011 determined that current fishing pressure on the yellowfin stock was at a safe level (IOTC, 2012). Nevertheless, there are uncertainties associated with the current approach to the IO yellowfin stock assessment, including the growth curve that is used (IOTC, 2012).

This study describes a hierarchical growth model for IO yellowfin that combines aging data derived from otolith readings, length-frequency data sampled from the European purse seine fishery over the last decade, and mark-recapture data collected through the Indian Ocean Tuna Tagging Program of the Indian Ocean (IOTTP). The influence of each data source on growth estimates was assessed by gradually increasing the model's complexity. Developed in a hierarchical Bayesian framework, our model explicitly accounts for the uncertainties associated with age estimates and length measurements. In addition, the model reflects expert opinion on two key areas: otolith reading and historical length and growth observations for yellowfin. In this study, we provide a flexible statistical framework that accounts for uncertainty in growth modeling and addresses a current concern of the IOTC.

\section{Material and methods}

We first describe the three datasets and the modeling approach used to estimate absolute age from multiple counts of otoliths. We then introduce the somatic growth model used for fitting the different datasets and we give technical details on the estimation procedure based on Bayesian inference. The parameters and variables used and the prior probability distributions are given in Tables 1 and 2, respectively. The subscripts $c, d, i, j, k$, and $r$ used in 
the equations indicate cohort, month, fish, capture event, otolith reading, and reader team, respectively. The symbol - indicates a multiplication term and the symbol $*$ used as exponent represents the observation of a variable.

\subsection{Mark-recapture data}

Mark-recapture data were collected during the Regional Tuna Tagging Program (RTTP-IO) that was the major component of the IOTTP (Hallier, 2008).

The tagging operations were carried out in the western Indian Ocean from 2005 to 2007 . During this time, a total of 64,323 yellowfin were tagged with dart tags. 2,741 of these fishes were also tagged with oxytetracycline (OTC), a chemical that leaves a permanent fluorescent mark in the calcified tissues. Tag recovery operations took place across the entire Indian Ocean basin. As at September 2012, 10,395 tagged yellowfin had been recovered, including 256 OTC-tagged fish (Sardenne et al., this issue). Most of the recoveries were reported for fish caught by the European purse-seine fleet (88\%). The pole and hand lines, gillnetters, longliners and troll lines were associated with low recovery rates (Carruthers et al., 2014). The range of dates associated with each recapture was derived from purse seiner logbook data and plans of brine-freezing tanks used for storing the tuna catch, and it was determined through close collaboration between the IOTC and purse seine fishing industry. The fork length $\left(F_{L}\right)$, i.e. fish length from the tip of the snout to the fork of the tail, was recorded to the nearest $0.5 \mathrm{~cm}$. At tagging, measurements were taken with a measuring board, while calipers were mostly used for recoveries.

Preliminary model runs including the $>4,000$ recaptures available from the RTTP-IO that were considered to be good following the screening criteria of the IOTC resulted in some convergence problems, likely due to the imbalance between the likelihoods components of the model and the large variability observed in growth increments over time. To circumvent this issue, the mark-recapture component of the growth model was mainly used to compensate for the lack of 
large fish in the other model components (see below). Thus, only fishes characterized by accurate date of recovery (i.e. no uncertainty in time-at-liberty) and size-at-recapture measured with great precision (i.e. at the Seychelles Fishing Authority lab facility) and $\geq 120 \mathrm{~cm} \mathrm{FL,} \mathrm{were} \mathrm{used.} \mathrm{The} 373$ yellowfin selected in the present study covered a large size range at tagging, i.e. between $44 \mathrm{~cm}$ and $113 \mathrm{~cm} F_{L}$, with distinct modes at about $50 \mathrm{~cm}, 60 \mathrm{~cm}$, and $90 \mathrm{~cm}$ (Fig. 1a). These tunas ranged in size between 120 and $159 \mathrm{~cm} F_{L}$ at recapture, having spent between 8 months and 5 years at sea (Fig. 1b).

\subsection{Aging data from otolith readings}

A total of 174 saggital otoliths were prepared and analyzed for aging purposes, comprised of (i) 128 fish, of which 124 were OTC-tagged, collected through the RTTP-IO program measuring between $43-72 \mathrm{~cm} F_{L}$ at tagging and 47.9-135.4 $\mathrm{cm} F_{L}$ at recapture, (ii) 28 fish collected from 2008-2009 from the Indian Ocean Tuna Ltd. (IOT) cannery measuring between 31-128.7 cm $F_{L}$ and (iii) 18 fish caught in 2007 through the West Sumatra Tuna Tagging Project (WSTTP) measuring between 19-29 cm $F_{L}$ (Anonymous, 2008).

Otoliths were prepared for age analysis following the method as described by Secor et al. (1991), Stéquert (1995), and Panfili et al. (2002). Transverse sections of saggital otoliths were examined by two teams of readers under a microscope (1000x magnification). Each team counted the daily growth micro-increments along the counting path, defined as the distance between the primordium (i.e. original point of growth) to the last micro-increment deposited (Morize et al., 2008; Sardenne et al., this issue). For the OTC-tagged fish, the number of micro-increments was counted for different otolith sections: (i) between the nucleus, i.e. the otolith core, and OTC mark $\left(I_{T}\right)$, (ii) between the OTC mark and otolith edge $\left(I_{M}\right)$ and (iii) between the nucleus and otolith edge $\left(I_{R}\right)$. In the remaining fish, otoliths were read in full, i.e., between the nucleus and otolith edge $\left(I_{R}\right)$. Each otolith was read between 2-5 times, giving a total of 521 otolith 
readings. Readers did not have prior knowledge of the size or time-at-liberty of the sampled individuals, thus ensuring that independence was maintained between the multiple readings (Morize et al., 2008; Sardenne et al., this issue).

Otolith aging techniques of fish are associated with counting errors and subjective interpretations by the reader. Both factors can lead to imprecision and bias in the age estimates generated (Neilson, 1992; Panfili et al., 2009). A hierarchical Bayesian model that accounted for process and interpretation errors was applied to estimate the age of each fish. The reader-specific stochastic processes associated with the preparation of the otoliths and their associated reading errors, $\eta$ and $\psi$, were modeled by choosing an error structure and eliciting informative prior density functions that were based on expert judgment (Table 2). The technical details of the aging model and the elicitation of prior distributions are fully described in Dortel et al. (2013). Initially, the number of micro-increments counted from the OTC mark to the otolith edge $\left(I_{M}\right)$ was related to the time-at-liberty $\left(T_{L}\right)$ to estimate the deposition rate accounting for the reading method and reader skills. This relationship was estimated for each fish $i$ and reader team $r$ following:

$$
I_{M_{i r}}=R_{r} \cdot T_{L_{i}}+\eta_{r}
$$

where $R$ represents the periodicity of micro-increment deposition in tuna otolith estimated by the reader team $r$ (i.e. it includes error related to reading interpretation) and $\eta$ represents an additive stochastic error related to the counting of micro-increments at otolith edge and dependent on reader team. Following expert judgment, the prior distribution of $\eta$ was assumed to follow a normal distribution with mean 0 and a standard deviation of 4 micro-increments (Table 2; Dortel et al. 2013). The parameter $R$ was assigned a $\beta$ dilated prior distribution in the estimation process (Table 2; Dortel et al. 2013).

The $k$ readings of $I_{M}$ of a same otolith were assumed to be independent 
and identically distributed (iid) around $I_{M_{i r}}$ following a normal distribution described by a multiplicative error in the reading process corresponding to a model of constant coefficient of variation (Sardenne et al., this issue):

$$
I_{M_{i r k}}^{*} \stackrel{i i d}{\sim} \mathcal{N}\left(I_{M_{i r}},\left(p_{r} \cdot I_{M_{i r}}\right)^{2}\right)
$$

where $I_{M_{i r k}}^{*}$ are the observed micro-increment counts from the OTC mark to the otolith edge for fish $i$, reader team $r$, and reading $k$ and $p_{r}$ corresponds to the relative percentage of misread otolith micro-increments for reader team $r$. The parameter $p_{r}$ was assigned a uniform prior distribution in the estimation process (Table 2).

The posterior distribution of the reader-specific deposition rate $R_{r}$ was subsequently used to estimate fish age using the multiple readings made for each otolith, assuming that the deposition rate estimated in equation 1 was constant and valid over the full fish lifespan. As the identification and interpretation of increments become increasingly difficult with increasing distance from the nucleus, there is more uncertainty around the counting of all increments than the counting of increments from the nucleus to the OTC mark. Thus, age estimates were preferentially derived from the number of increments from the nucleus to the OTC mark $I_{T_{i r}}$. The fish age at tagging $A_{T_{i r}}$ was assessed following:

$$
I_{T_{i r}}=R_{r} \cdot A_{T_{i r}}+\psi_{r}
$$

where $I_{T}$ is the number of increments from the nucleus to the OTC mark and $\psi$ is an additive stochastic error related to the counting of micro-increments near the nucleus, which may occur during preparation due to excessive sanding of the otolith section. This error was assumed to be dependent on reader team and assigned a normal prior distribution with mean 0 and a standard deviation of 3 micro-increments (Table 2). Similarly to $I_{M}$, the multiple readings $k$ of $I_{T}$ were assumed to be normally distributed around $I_{T_{i r}}$ following: 


$$
I_{T_{i r k}}^{*} \stackrel{i i d}{\sim} \mathcal{N}\left(I_{T_{i r}},\left(p_{r} \cdot I_{T_{i r}}\right)^{2}\right)
$$

where $I_{T_{i r k}}^{*}$ are the observed micro-increment counts from the nucleus to the OTC mark for fish $i$, reader team $r$, and reading $k$.

Age at recovery $\left(A_{R}\right)$ was estimated as the addition of age at tagging $\left(A_{T}\right)$ and time-at-liberty $\left(T_{L}\right)$. For the recoveries characterized by some uncertainty on the date of recapture (see Section 2.1), $T_{L_{i}}$ was assumed to follow a uniform distribution on the interval $\left[T_{L_{1 i}}^{*}, T_{L_{2 i}}^{*}\right]$, where $T_{L_{1 i}}^{*}$ and $T_{L_{2 i}}^{*}$ were the minimal and the maximal time-at-liberty observed, respectively. For any fish that did not have OTC-marked otoliths, so that $I_{T}$ was not available, the fish age at recovery $A_{R_{i r}}$ was derived from $I_{R}$ following:

$$
I_{R_{i r}}=R_{r} \cdot A_{R_{i r}}+\psi_{r}+\eta_{r}
$$

where $I_{R}$ is the total increment count and $\psi$ and $\eta$ are the reader-dependent stochastic errors at the nucleus and otolith edge, respectively. The $k$ readings of $I_{R}$ of fish $i$ by reader team $r$ were assumed to be normally distributed following:

$$
I_{R_{i r k}}^{*} \stackrel{i i d}{\sim} \mathcal{N}\left(I_{R_{i r}},\left(p_{r} \cdot I_{R_{i r}}\right)^{2}\right)
$$

where $I_{R_{\text {irk }}}^{*}$ are the observed micro-increment counts from the nucleus to the otolith edge for fish $i$, reader team $r$, and reading $k$. The age at tagging $\left(A_{T}\right)$ could then be derived from $A_{R}-T_{L}$.

2.3. Modal progression from length-frequency data

Length-frequency data were collected from commercial catches of European, Seychelles and Iranian purse seiners between December 2000 and March 2010 (Floch et al., 2012). The monthly length-frequency distributions exhibited various modes which assumed to correspond to different cohorts. The length progression of each mode was then monthly tracked to provide both mean age 
$F_{L}(A)=L_{\infty}\left(1-\exp \left(-k_{2} \cdot\left(A-t_{0}\right)\right) \cdot\left(\frac{1+\exp \left(-\beta\left(A-t_{0}-\alpha\right)\right)}{1+\exp (\beta \cdot \alpha)}\right)^{\frac{k_{1}-k_{2}}{\beta}}\right)$

and length estimates of Indian Ocean yellowfin population (Pauly and Morgan, 1987). To optimize the identification of the modes, the length distributions of the various cohorts in a given month were considered as a set of overlapping normal distributions (Hasselblad, 1966; Schnute and Fournier, 1980). A mixture of normal distributions was fitted with the mix function applied in the mixdist package of the statistical software R version 2.12.1 (R Development Core Team, 2010), using an Expectation-Maximization algorithm (Macdonald and Green, 1988). The normalmixEM function of the mixtools package was used to define the initial values for the means and standard deviations of each of the length distributions. The standard deviation was constrained to increase with the mean length. This was done to account for overlaps between two successive lengthat-age distributions which are exacerbated by a slower growth and an increased individual variability with increasing age. The smallest length modes were identified as the recruitment peak of each cohort of the Indian Ocean yellowfin.

\subsection{Modeling somatic growth using Bayesian inference}

A hierarchical Bayesian model was implemented to estimate yellowfin growth by gradually adding data from the three different sources. The Von Bertalanffy $\log \mathrm{K}$ model (VB $\log \mathrm{K})$, currently used for Indian Ocean yellowfin stock assessment (IOTC, 2012), was considered. This model can account for two growth phases through a logistic function that links the two distinct growth rates coefficient $k_{1}$ and $k_{2}$ (Laslett et al., 2002; Eveson et al., 2004). The fork length of a fish at an age $A, F_{L}(A)$, is described as: where $L_{\infty}$ is the asymptotic length, i.e. the maximum length that a fish can reach, $\alpha$ is the inflection point, i.e the age relative to $t_{0}$ at which the change in growth rate occurs and $\beta$ is the parameter that controls the transition rate 


$$
F_{L_{i j}}^{*}=L_{\infty}\left(1-\exp \left(-k_{2} \cdot\left(A_{i j}-t_{0}\right)\right) \cdot\left(\frac{1+\exp \left(-\beta\left(A_{i j}-t_{0}-\alpha\right)\right)}{1+\exp (\beta \cdot \alpha)}\right)^{\frac{k_{1}-k_{2}}{\beta}}\right) \cdot \vartheta_{i j}+\varepsilon_{i j}
$$

271

between the growth rates $k_{1}$ and $k_{2}$ (Table 1 ).

\subsubsection{Model fit to aging data}

The VB $\log \mathrm{K}$ growth model was used to link the observations of yellowfin length to age estimates derived from otolith counts, taking into account measurement errors at different levels of the observation process and process error linked to environmental and inter-individual variability. Indeed, the different datasets included measurements errors in length (at tagging and recovery), micro-increment counts, and time-at-liberty. In addition, the asymptotic length, the growth rate as well as the age at which the change in growth occurs depend on environmental conditions, food availability and the intrinsic characteristics of fish, which likely to vary from one fish to another. This eventually results in individual growth curves that do not conform exactly to the pattern described by Eq. 7.

Following Eq. 7, the observed fork length $F_{L_{i j}}^{*}$ of fish $i$ at capture event $j$ was modeled as:

where $A_{i j}$, the age of fish at capture event $j$, was estimated from otolith readings using the aging error model which was used to propagate age uncertainty into growth parameter estimates (Eqns. 1-6). The process errors, $\vartheta_{i j}$ were assumed to follow a log-normal distribution with mean 0 and a common variance, $\sigma_{\vartheta}^{2}$. The length measurement errors, $\varepsilon_{i j}$, were assumed to be independent and normally distributed around 0 with a common variance, $\sigma_{j}^{2}$. The length measurement errors at tagging, $\varepsilon_{i 1}$, were assessed from RTTP-IO fish released and recaptured several times with $T_{L} \leq 7$ days. These individuals were 
not included in the subsequent analyses and therefore constitute an independent dataset. The fork length differences between successive measurements of the same fish for the subset of yellowfin selected, $\Delta L^{*}$, were assumed to be independent and follow the same distribution as $\varepsilon_{1}$, i.e. a normal distribution 284 around 0 with standard deviation $\sigma_{1}$ :

$$
\Delta L^{*} \stackrel{i i d}{\sim} \mathcal{N}\left(0, \sigma_{1}^{2}\right)
$$

At recovery, the fork lengths were often measured on frozen fish in brine, which could result in an additional error to length measurements. The length measurement errors at recovery $\varepsilon_{i 2}$ were calculated as the sum of the measurement errors at tagging $\left(\varepsilon_{i 1}\right)$ and measurement errors associated with freezing $\left(\varepsilon_{i f}\right)$. This latter error was assumed to be normally distributed around 0 with a standard deviation $\sigma_{f}$ which was estimated using fish that were measured frozen and then thawed and re-measured with excellent precision following:

$$
\Delta S^{*} \stackrel{i i d}{\sim} \mathcal{N}\left(0, \sigma_{f}^{2}\right)
$$

where $\Delta S^{*}$ represents the fork length differences between frozen and fresh measurements of the same fish $i$.

\subsubsection{Model fit to modal progression}

The modal progressions estimated from the length-frequency distributions can be treated as multiple mark-recapture events where the initial age is known. Let $\mu_{c d}$ the value of the modal length for cohort $c$ at month $d$, and $a_{c 1}$ the age of the first mode. As the time interval between two successive length modes was one month, the corresponding age $(a)$ for the modal length $\mu_{c d}$ was $a_{c d}=$ $a_{c 1}+(d-1) / 12$. Following Eq. 7, the observation of modal length $\mu_{c d}^{*}$ of cohort $c$ at month $d$ was written: 
$\mu_{c d}^{*}=L_{\infty}\left(1-\exp \left(-k_{2} \cdot\left(a_{c 1}+(d-1) / 12-t_{0}\right) \cdot\left(\frac{1+\exp \left(-\beta\left(a_{c 1}+(d-1) / 12-t_{0}-\alpha\right)\right)}{1+\exp (\beta \cdot \alpha)}\right)^{\frac{k_{1}-k_{2}}{\beta}}\right) \cdot \xi_{\mu_{c d}}\right.$

303

$F_{L_{i 2}}^{*}=L_{\infty}-\left(L_{\infty}-F_{L_{i 1}}^{*}\right)\left(\exp \left(-k_{2} \cdot T_{L_{i}}^{*}\right) \cdot\left(\frac{1+\exp \left(-\beta\left(A_{T_{i}}+T_{L_{i}}^{*}-t_{0}-\alpha\right)\right)}{1+\exp \left(-\beta\left(A_{T_{i}}-t_{0}-\alpha\right)\right)}\right)^{\frac{k_{1}-k_{2}}{\beta}}\right) \cdot \varphi_{i}+\varepsilon_{i 2}$

322

where all parameters are defined in Table 1 . The uncertainty around the value of the modal length, associated with the identification of mode, was assumed to increase with the length value, resulting in a typical multiplicative error term $\left(\xi_{\mu_{c d}}\right)$. This error term combines both the process error and the uncertainty around the value of the modal length of cohort $c$ at month $d$. The errors $\xi_{\mu_{c d}}$ were assumed to follow a log-normal distribution with mean 0 and a common variance $\sigma_{\xi}^{2}$. Gamma prior distributions were used for the ages of first mode $\left(a_{c 1}\right)$ based on the month of detection. An age uncertainty of 3-4 months was considered for each age as yellowfin has a seasonal sexual activity characterized by two distinct periods in Indian Ocean, a main spawning season from November to February with a peak in January and a second minor spawning period from June to August (Stéquert et al., 2001; Zhu et al., 2008; Zudaire et al., 2013).

\subsubsection{Model fit to mark-recapture data}

Following Eq. 7, the fork length at recapture $F_{L_{i 2}}^{*}$ can be expressed as a function of the length at tagging $F_{L_{i 1}}^{*}$, the age at tagging $A_{T_{i}}$ and the time-atliberty $T_{L_{i}}^{*}$ for each fish $i$ :

where $k_{1}, k_{2}, \alpha, \beta, t_{0}$, and $L_{\infty}$ are the parameters of the VBlogK growth model, $\varepsilon_{i 2}$ are the length measurements errors at recovery (see Section 2.4.1) and 
$\varphi_{i}$ are the process errors for the mark-recapture data (Table 1). These errors were assumed to follow a log-normal distribution with mean 0 and a common variance $\sigma_{\varphi}^{2}$. The mark-recapture data were not used to update the posteriors of the age-dependent parameters, i.e. $\alpha$ and $t_{0}$, since they do not provide any information on the absolute age. Information for these parameters was provided through the aging and length-frequency data.

\subsubsection{Prior distributions and Bayesian inference}

The prior distributions of the growth model parameters were assumed to be independent and were specified as being weakly informative or uninformative (Table 2). An exception to this was the asymptotic length, $L_{\infty}$, which was assigned an informative prior using a generalized extreme value (GEV) distribution. The GEV distribution allows the extrapolation of the behavior of the distribution tails from the greatest values of a sample, and thus estimates the occurrence probability of extreme events (Borchani, 2010). $L_{\infty}$ can be interpreted as the maximal length reached by the oldest fishes. As tunas grow throughout their lives, the largest observed sizes were assumed to correspond to the oldest fishes, which motivated the choice of using the GEV distribution. The GEV distribution was fitted to a data set containing records of the largest fish collected between 1952-2011 from the European and Seychelles purse seiners, Maldivian pole and liners, and Taiwanese and Japanese longliners (Dortel et al., 2013).

The growth rate coefficients, $k_{1}$ and $k_{2}$, are, in part, model-specific. For $k_{1}$, a weakly informative gamma distribution was assigned from values published in the literature (Table A1). $k_{2}$ was set equal to $k_{1}+\kappa$ with $\kappa$ following a uniform distribution. The age $\alpha$, which is relative to $t_{0}$, was assigned a weakly informative gamma distribution defined from results of studies that considered a two-stanza growth curve (Gaertner and Pagavino, 1991; Gascuel et al., 1992; Lehodey and Leroy, 1999; Lumineau, 2002; Viera, 2005). The parameters $\beta$, which is specific to the VBlogK model, and $t_{0}$, which depends on the data, 
were assigned uniform distributions. The standard deviations of the length measurement errors at tagging, $\sigma_{1}$, the errors associated with freezing, $\sigma_{f}$, and the process errors $\sigma_{\vartheta}, \sigma_{\xi}, \sigma_{\varphi}$, were assigned uninformative priors through using inverse gamma distributions (Table 2).

A hyperprior for the parameters of overall age-at-tagging distribution was considered for the 373 yellowfin considered in the mark-recapture likelihood component of the model. The ages-at-tagging $\left(A_{T_{i}}\right)$ were assumed to follow a gamma prior distribution (Cope and Punt, 2007). The influence of the choice of the prior distribution on the growth curve estimation was assessed by considering a log-normal distribution for the overall age-at-tagging distribution (Eveson et al. 2004). The parameters of the two prior distributions are given in Table 2 .

The growth parameters, fish ages and associated error estimations were evaluated by Markov Chain Monte Carlo (MCMC) simulations using a Metropoliswithin-Gibbs sampling algorithm as implemented in OpenBUGS version 3.2.1 (Spiegelhalter et al., 2011). Three chains starting at contrasting initial values were considered to check for the convergence of the algorithm. First, the growth model was fitted to the otolith age estimates and fish length (Model 1). The length-frequency data were then added to the growth model as a second likelihood component (Model 2). Finally, the mark-recapture data were included as a third likelihood component (Model 3). Model 3 was fitted to the 3 data sources with either the gamma or the log-normal prior distribution for the agesat-tagging. For each model, the convergence of the MCMC to the stationary posterior distribution was evaluated by the Gelman-Rubin diagnostic, based on the ratio of inter-chain variance to intra-chain variance. A ratio close to 1 indicates convergence (Gelman and Rubin, 1992). The performance of each model was checked based on 1,500,000 samples from the joint posterior distribution generated from MCMC simulation. The ratio was computed from second half of MCMC simulation sample. The main statistics of the marginal posterior dis- 
tributions (mean, mode, standard deviation, and 95\% Bayesian posterior credibility interval) were computed after rejecting a burn-in period of 5,000 samples and a thinning by drawing every $2,500^{\text {th }}$ sample. The code of the integrated model is given in Appendix B.

\section{Results}

\subsection{Modal progression analysis}

Twenty one yellowfin cohorts ranging in size from $35-130 \mathrm{~cm} F_{L}$ were identified by tracking the montly progression of length modes in length-frequency histograms for the period 2000-2010 (Figure 2). Recruitment to the purse seine fishery peaks occured at approximately $35.8 \mathrm{~cm} F_{L}(\mathrm{SD}=1.7 \mathrm{~cm})$ from February to August. A clear pattern in the month of recruitment was not apparent from the data of the studied period. Linkages between successive modes assumed as belonging to the same cohort proved to be difficult to establish above $70 \mathrm{~cm} F_{L}$. This was due to the lack of intermediate-sized fish caught, between $70-90 \mathrm{~cm} F_{L}$, and the general absence of clearly identifiable modes in the length distributions of large tunas, i.e. $>90 \mathrm{~cm} F_{L}$. The increase in modal length across cohorts over time showed strong inter-annual variability (Figure 2). Some cohorts showed an apparent decrease in growth rates at around $50 \mathrm{~cm} F_{L}$, followed by a faster growth above $60 \mathrm{~cm} F_{L}$ (e.g. cohort 9), while the growth rates appeared more linear for other cohorts (e.g. cohorts 7).

\subsection{Statistical inference}

The joint posterior distribution was considered to be stationary as indicated by the Gelman-Rubin diagnostic of convergence which approached a value of 1 , and by the three MCMC chains that mixed well for each parameter of the three models. For each model, the data provided information on most of the parame-

ters, i.e. the posterior distributions were narrower than the prior distributions, 
with the exception of $\beta$ (Figure 3). The precision in the parameter estimates increased as each dataset provided an increasing amount of information (Table 3). The marginal posterior distributions became increasingly narrow as the level of input information increased from model 1 , based on otolith data only to model 3 which used all three data types (otolith, length-frequency, and markrecapture). However, although the addition of data beyond improved by the information added to the otolith data was beneficial, the transition rate, $\beta$, in model 3 was poorly estimated. This was indicated by its posterior distribution which was irregular and characterized by a large variance (Figure 3).

The gradually increasing number of observations from model 1 to 3 led to an overall decrease in the process error and uncertainty around the mean curve (Figure 4). However, while models 2 and 3 proved effective in estimating the initial age of each cohort identified in the length-frequency dataset, model 3 was unable to accurately estimate the ages of yellowfin from the mark-recapture data. Uncertainty around estimates of ages-at-tagging was high, i.e. the coefficient of variation ranged between $46 \%$ and $118 \%$. No clear relationship was found between length and estimates of age-at-tagging, the age posterior means being characterized by a large range of 1-3.5 years in the interval $50-70 \mathrm{~cm} F_{L}$ (Figure 4c-d). Age-at-tagging estimates then showed some apparent inconsistency with the ages derived from otolith and length-frequency data. The choice of prior distribution had a strong impact on age estimation. Age estimates based on the prior gamma distribution ranged between 0.8 and 3.6 years without any clear mode while the use of the prior log-normal distribution resulted in a smaller age range with a distinct mode of the posterior means at about 2.5 years (Figure 5).

Overall and despite the difficulties of the model in estimating ages for the mark-recapture component, the prior distribution used for the ages-at-tagging had a small impact on the growth estimate of yellowfin tuna. The growth parameters based on the gamma and log-normal distributions were very similar, 
${ }_{446}$ (Table 4 and Figure 6).

447

\subsection{Indian Ocean yellowfin growth}

Growth parameter estimates for Indian Ocean yellowfin were found to vary according to the amount of information input into each model. For each of the three models, two distinct growth phases were observed over the yellowfin lifespan (Figure 6). The growth rate coefficients, $k_{1}$ and $k_{2}$ significantly differed according to the Bayesian 95\% credibility interval for each model (Table 3). The first phase was characterized by a relatively slow growth rate that gradually decreased to a minimum rate of $1.77 \mathrm{~cm} \mathrm{month}^{-1}$ at 1.96 years $\left(68 \mathrm{~cm} F_{L}\right), 1.5 \mathrm{~cm}$

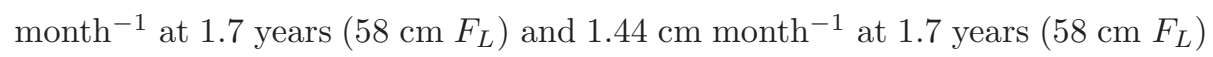
for models 1 to 3 respectively. In the second phase, the growth rate accelerated, reaching maximum rates of $4.3 \mathrm{~cm} \mathrm{month}^{-1}$ at 2.5 years $\left(85 \mathrm{~cm} F_{L}\right), 5.1 \mathrm{~cm}$ month $^{-1}$ at 2.16 years $\left(74 \mathrm{~cm} F_{L}\right)$ and of $6.3 \mathrm{~cm} \mathrm{month}^{-1}$ at 2.13 years $(74 \mathrm{~cm}$ $F_{L}$ ) for models 1 to 3 , respectively. Thereafter, the growth rate progressively decreased with increasing size and approached 0 close to asymptotic length.

The different datasets provided little information on the $\beta$ parameter whose posterior mean was found to be $>16$ in each of the three models, suggesting that the transition between the growth stanzas occured rapidly, less than six months (Table 3). The mean posterior of age $\alpha$ at which this transition occurred varied between 2 and 2.3 years, which corresponded to 76,66 and $66 \mathrm{~cm}$ $F_{L}$ for models 1 to 3 respectively. The asymptotic length $L_{\infty}$, described by a mean prior value of $173 \mathrm{~cm} F_{L}$, decreased from a posterior mean of $168 \mathrm{~cm} F_{L}$ for model 1 to $156 \mathrm{~cm} F_{L}$ for model 2 and 138-139 $\mathrm{cm} F_{L}$ for model 3 (Figure 4). 


\section{Discussion}

To our knowledge, this study presents the most comprehensive analysis of yellowfin growth in the Indian Ocean by combining the best information currently available from a variety of data sources collected at both the population and individual levels. These data encompassed about 600,000 length measurements of yellowfin caught by purse seiners over a 10-years period, which we used to track monthly changes in the modal length of age classes. In addition, information on yellowfin growth was provided through the use of more than 370 individual growth rate values derived from accurate times-at-liberty and more than 500 otolith readings. To take advantage of these varied data sources, we developed an integrated model that exploited all the available information and took explicitely into account the various observation and process errors associated with the growth estimation. Despite estimation difficulties encountered with the mark-recapture dataset, we argue that the resulting growth curves are an improvement of the one currently used in the Indian Ocean yellowfin stock assessments.

Most previous studies on Indian Ocean yellowfin growth used a single data source, especially length-frequency data (Mohan and Kunhikoya, 1985; Marsac, 1991; Viera, 2005) or direct age estimates from vertebrae or otoliths (Romanov and Korotkova, 1988; Stéquert et al., 1996), and sometimes mark-recapture data (Fonteneau and Gascuel, 2008). The collection processes for each of the data sources are very different and associated with inherent uncertainties that can make comparisons between growth curves difficult. Sampling differences, i.e. size-range, gear selectivity and spatio-temporal coverage, observation errors and the process that is being observed itself, e.g. variability in the deposition rates of growth rings in fish otoliths, are all factors that can give rise to these uncertainties. However, the use of an integrated approach enables the different data sources to complement each other, thus providing a more robust estimation of growth (Eveson et al., 2004; Restrepo et al., 2010). In this study, growth was 
estimated by gradually adding data from the three different sources into the statistical model, allowing to appraise their individual contribution to the final estimations. At first, the model was fitted to aging data derived from otolith readings. Our model explicitly accounts for the uncertainties and biases associated with estimating fish growth from otolith readings, especially uncertainties related to the estimation of age. In a previous study, Dortel et al. (2013) showed through simulation that the modeled ages were reliable.

In a second step, the most comprehensive length-frequency dataset available for Indian Ocean yellowfin was added to the growth model. The addition of the likelihood component improved the overall parameters estimation and resulted in a smaller asymptotic length, $L_{\infty}$, a larger second-stanza growth rate coefficient, $k_{2}$, and a more pronounced transition between the two growth stanzas. Growth studies conducted over the last few decades on Indian Ocean yellowfin growth using length-frequency data generally support a two-stanza growth rate pattern (Marcille and Stéquert, 1976; Marsac and Lablache, 1985; Anderson, 1988; Marsac, 1991; Firoozi and Carrara, 1992; Lumineau, 2002; Viera, 2005). However, the length frequency data sampled from commercial fisheries catches are dependent on size-selectivity of fishing gear, fishing areas and fish schooling behavior. Therefore, these data can not be considered as a representative random sample of the population (Longhurst and Pauly, 1987). In particular, size-based fishing selectivity has been shown to produce bias in length-at-age samples. The bimodal size-selectivity associated with purse seine sets may result in the over-representation of young fast-growing fish and old slow-growing fish in size-age samples. This in turn may entail bias in growth estimations resulting in an apparent growth deceleration and unrealistic estimates of asymptotic length (Lucena and O'Brien, 2001; Taylor et al., 2005). We did not account for selectivity effects in this study as we were focused on the available harvestable population only (Roa-Ureta, 2010; Taylor et al., 2005). Our growth estimates might however be affected by the low reporting rates of tagged tunas from longliners (Carruthers et al., 2014) which target yellowfin and bigeye in 
waters deeper than that of purse seiners. In the case of yellowfin, this should not affect much the growth estimate as the length composition of purse seine and longline catches for yellowfin is very similar for fishes $>100 \mathrm{~cm} F_{L}$ (Carruthers et al., 2014). In addition, the identification of modes that becomes increasingly difficult with increasing size may affect the growth parameter estimates. In this analysis, proportions of length-at-age were derived using a mixture of normal distributions fitted to the length-frequency data. This is to optimize the identification of modes and account for uncertainties associated with yellowfin age. Nevertheless, some subjectivity remains in the assignment of a mode to a particular cohort.

Finally, mark-recapture data were introduced to the growth model. Such data generally provide valuable information on growth variability between individuals. The majority of fish growth studies that use mark-recapture data are however based on the von Bertalanffy model, which assumes a linear decrease in growth rate over the lifespan of a fish (von Bertalanffy, 1938). The shape of the growth curve can then be estimated without prior knowledge of age using the Fabens method (Fabens, 1965) or alternative Fabens-type approaches (Wang, 1998). These methods express the change in length of a fish as a function of its time-at-liberty. However, these methods can not be applied to more complicated multi-stanza growth models, such as the VBlogK model, where the transition between the various growth phases is related to age parameters (Laslett et al., 2002; Eveson et al., 2004).

In our study, only the larger fish of the mark-recapture dataset were considered to complement the otolith and length-frequency datasets with regards to the asymptotic part of the curve. Although the tagging operations of the RTTP-IO were only performed in the western Indian Ocean, yellowfin selected in the present analysis spent between 8 months and 5 years at sea, i.e. most of them were recovered after a mixing period larger than 12 months which is considered sufficient for the tagged fish to adequately disperse throughout the 
entire population (Langley and Million, 2012). Based on a frequentist approach, Eveson et al. (this issue) who used a larger number of mark-recapture data also encountered some estimation problems due to the imbalance between the likelihoods components of the model. In our analysis, aging data were however insufficient to compensate for the lack of information on age in mark-recapture observations. Hence, our results showed that ages estimated for the fishes tagged and recaptured with such a complex growth curve were poorly estimated. In addition, the model including the three sources of information forecasted a mean asymptotic length of about $138 \mathrm{~cm} F_{L}$, which was comparatively low to the maximum lengths historically reported for yellowfin in the Indian Ocean.

Our modeling approach differs in several key points to the statistical model of Eveson et al. (this issue). Firstly, we considered the uncertainty in age estimations derived from otolith counts using an aging error model. This error model has been shown to outperform methods that use an average age derived from multiple otolith counts (Cope and Punt, 2007; Dortel et al., 2013). Secondly, we used length-frequency data while Eveson et al. (this issue) only used otolith and mark-recapture data. However, we only selected fish with accurate time-at-liberty values in the likelihood component of the mark-recapture data to ensure that the sources of variability in the model were decreased. By contrast, Eveson et al. (this issue) used more than 4,300 mark-recapture data for yellowfin. Thirdly, we included process error in our model to account for individual variability in the whole growth term, whilst Eveson et al. (this issue) considered that individual variability was mainly driven by differences in individual $L_{\infty}$. Finally, we used Bayesian inference to account for historical observations of the largest yellowfin caught in Indian Ocean fisheries to provide information on $L_{\infty}$. Indeed, little information was provided to the asymptotic length, $L_{\infty}$, due to the small number of large individuals $\left(>130 \mathrm{~cm} F_{L}\right)$ in the dataset.

Overall, the resulting growth curves of both approaches demonstrate that Indian Ocean yellowfin tuna exhibits a more complex growth pattern than ex- 
pected by the classical von Bertalanffy growth model. Integrated statistical models appear to be a useful approach to combine all available information within a unifying framework and allow for the functional form of growth to be described in a holistic manner (Eveson et al., 2004). However, statistical models exhibit limitations when dealing with complex growth patterns when aging data are only provided through time-consuming and expensive methods (e.g., otolith analysis). Furthermore, they do not provide insights into the biological and ecological mechanisms that lie behind the growth stanzas. Several assumptions have been put forward to explain the growth acceleration observed from around $70 \mathrm{~cm}$ which results in the second growth rate parameter $k_{2}$ to be higher than $k_{1}$ (Fonteneau, 1980; Bard, 1984; Gaertner and Pagavino, 1991; Lehodey and Leroy, 1999). However the underlying mechanisms have been little studied and are not yet well understood. To our opinion, the acceleration could be related to the transition from the aggregating schooling behaviour of juveniles of yellowfin in warm surface waters to a more mobile state in offshore and deeper waters. According to fisheries observations, yellowfin leave the multispecies schools associated with drifting fish aggregating devices at sizes close to that forecasted for the growth acceleration (Bard, 1984). This results in some difficulty to identify length modes for fish $>70 \mathrm{~cm}$ from the length-frequency data. Changes in habitat combined with ontogenetic physiological changes (e.g. acquisition of thermoregulation ability) could then reduce the intra- and interspecific competition experienced in schools and modify the diet of yellowfin through niche expansion (Fonteneau, 1980). The second phase characterized by faster growth for yellowfin corresponds to the length range $(55-120 \mathrm{~cm})$ during which almost all females reach maturity (Zudaire et al., 2013). Future modeling work could focus on alternative approaches aimed at expressing age as a function of fish length and to understanding kinetic energy transfers in fish over time. Bioenergetic models that explicitly represent the allocation of metabolic energy between growth, maintenance, and reproduction might provide a way forward (West et al., 2001; Jusup et al., 2011). 


\section{Acknowledgements}

The tuna tagging data analyzed in this work were collected under the Indian Ocean Tuna Tagging Programme (IOTTP) comprising the Regional Tuna Tagging Project of the Indian Ocean funded under the 9th European Development Fund (9.ACP.RSA.005/006) of the European Union, and small-scale tagging projects funded by the European Union and the Government of Japan such as the West Sumatra Tuna Tagging Project. We wish to acknowledge the contributions of all the people who have been involved in the IOTTP. This study was funded by the European Union (Reg. 199/2008, 665/2008 and SI2.604453), ORTHONGEL and the French Ministry of Agriculture and Fisheries (301629/00), and the Institut de Recherche pour le Développement through grants to FS and ED. We are grateful to Eric Morize, Jean-Marie Munaron, Carys Davies, Claire Geffroy and Eric Dabas for their contribution to otolith analyses. We particularly thank Jean-Pierre Hallier and Alain Fonteneau for their dedication to the IOTTP, their continuous support and sharing of stimulating ideas on tuna research. F Massiot-Granier participated in the initial steps of growth modelling. We are grateful to the three anonymous reviewers who contributed to the improvement of the paper. The manuscript benefited from fruitful discussions with Paige Eveson. This work is a contribution of the Agence Nationale de la Recherche EMOTION project (ANR 11 JSV7 007 01).

Amstrup, S., T. McDonald, and B. Manly. 2005. Handbook of CaptureRecapture Analysis. Princeton University Press.

Anderson, R. 1988. Growth and migration of juvenile yellowfin tuna (Thunnus albacares) in the central Indian Ocean. IPTP Collective volume of working documents 21:28-39.

Anonymous. 2008. West Sumatra Tuna Tagging Project 2006-2007, Final Report. Technical report.

Bard, F. 1984. Croissance de l'albacore (Thunnus albacares) Atlantique d'aprés 
les données des marquages. ICCAT Collective Volume of Scientific Papers 20:104-116.

Bard, F., N. Chabanet, and N. Caouder. 1991. Croissance du thon albacore (Thunnus albacares) en Océan Atlantique estimées par marquages. ICCAT Collection Volume of Scientific Papers 36:182-204.

Borchani, A. 2010. Statistiques des valeurs extrêmes dans le cas de lois discrètes. Technical Report ESSEC Working Paper 10009, ESSEC Business School.

Campana, S. E. 2001. Accuracy, precision and quality control in age determination, including a review of the use and abuse of age validation methods. Journal of Fish Biology 59:197-242.

Carruthers, T., A. Fonteneau, and J.-P. Hallier. 2014. Estimating tag reporting rates for tropical tuna fleets of the indian ocean. Fisheries Research 155:2032.

Clark, J. S. 2005. Why environmental scientists are becoming Bayesians. Ecology Letters 8:2-14.

Cope, J., and A. Punt. 2007. Admitting ageing error when fitting growth curves: an example using the von bertalanffy growth function with random effects. Canadian Journal of Aquatic and Fisheries Sciences 64:205-218.

Cotter, A., L. Burt, C. Paxton, C. Fernandez, S. Buckland, and J. Pan. 2004. Are stock assessment methods too complicated? Fish and Fisheries 5:235254.

Davidoff, E. 1963. Size and year class composition of catch, age and growth of yellowfin tuna in the eastern tropical Pacific Ocean. Inter-American Tropical Tuna Commission Bulletin 8:199-251.

Diaz, E. 1963. An increment technique for estimating growth parameters of tropical tunas, as applied to yellowfin tuna (Thunnus albacares). Inter-American Tropical Tuna Commission Bulletin 8:383-416. 
Dortel, E., F. Massiot-Granier, E. Rivot, J. Million, J. Hallier, E. Morize, J. Munaron, N. Bousquet, and E. Chassot. 2013. Accounting for age uncertainty in growth modeling, the case study of yellowfin tuna Thunnus albacares of the Indian Ocean. PLoS ONE 8:1-12.

Draganik, B., and W. Pelczarski. 1984. Growth and age of bigeye and yellowfin tuna in the central Atlantic as per data gathered by R/V "WIECZNO". ICCAT Collection Volume of Scientific Papers 20:96-103.

Eveson, J., J. Million, F. Sardenne, and G. Le Croizier. this issue. Estimating growth of tropical tunas in the Indian Ocean using tag-recapture data and otolith-based age estimates. Fisheries Research .

Eveson, J. P., G. M. Laslett, and T. Polacheck. 2004. An integrated model for growth incorporating tag-recapture, length-frequency, and direct aging data. Canadian Journal of Aquatic and Fisheries Sciences 61:292-306.

Fabens, A. 1965. Properties and fitting of the Von Bertalanffy growth curve. Growth 29:265-289.

Firoozi, A., and G. Carrara. 1992. An analysis of lengh-frequencies of Thunnus albacares in Iranian waters. IPTP Collective volume of working documents 8:95-102.

Floch, L., A. Delgado de Molina, C. Assan, P. Dewals, J. Areso, and E. Chassot. 2012. Statistics of the European purse seine fishing fleet and associated flags targeting tropical tunas in the Indian Ocean (1981-2011). IOTC Working Party of Tropical Tuna IOTC-2012-WPTT14-22:32 p.

Fonteneau, A. 1980. Croissance de l'albacore (Thunnus albacares) de l'Atlantique Est. ICCAT Collective Volume of Scientific Papers 9:152-168.

Fonteneau, A. 1981. Dynamique de la population d'Albacore (Thunnus albacares, bonnaterre, 1788) de l'océan atlantique. Ph.D. thesis, ORSTOM, Paris. 
Fonteneau, A. 2010. Atlas des pécheries thoniéres de l'Océan Indien = Atlas of Indian Ocean tuna fisheries. IRD, Marseille.

Fonteneau, A., and D. Gascuel. 2008. Growth rates and apparent growth curves, for yellowfin, skipjack and bigeye tagged and recovered in the Indian Ocean during the IOTTP. IOTC Working Party of Tagging Data Analysis 8:23p.

Fournier, D., and C. P. Archibald. 1982. A general theory for analyzing catch at age data. Canadian Journal of Aquatic and Fisheries Sciences 39:1195-1207.

Gaertner, D., and M. Pagavino. 1991. Observation sur la croissance de l'albacore (Thunnus albacares) dans l'Atlantique Ouest. ICCAT Collection Volume of Scientific Papers 36:479-505.

Gascuel, D., A. Fonteneau, and C. Capisano. 1992. Modélisation d'une croissance en deux stances chez l'albacore (Thunnus albacares) de l'Atlantique Est. Aquatic Living Resources 5:155-172.

Gelman, A., and D. Rubin. 1992. Inference from iterative simulation using multiple sequences. Statistical Science 7:457-511.

Green, B., B. Mapstone, G. Carlos, and G. Begg. 2009. Tropical otoliths - where to next?, volume Methods and Technologies in Fish Biology and Fisheries 11 of Tropical Fish Otoliths: Information for Assessment, Management and Ecology. Springer, Green, Mapstone, Carlos and Begg, Dordrecht.

Hallier, J. 2008. Status of the Indian Ocean tuna tagging programme - RTTPIO. IOTC Working Party of Tagging Data Analysis 10:40p.

Hampton, J. 2000. Natural mortality rates in tropical tunas: size really does matter. Canadian Journal of Fisheries and Aquatic Sciences 57:1002-1010.

Hasselblad, V. 1966. Estimation of parameters for a mixture of normal distributions. Technometrics 8:431-444. 
Hennemuth, R. 1961. Size and year class composition of catch, age and growth of yellowfin tuna in the eastern tropical pacific ocean. Inter-American Tropical Tuna Commission Bulletin 5:1-112.

Herrera, M., and L. Pierre. 2010. Status of IOTC databases for tropical tunas. Proceedings of the Twelfth session of the IOTC Working Party on Tropical Tunas, Victoria, Seychelles 18-25 October 2010, IOTC-2010-WPTT03:28p.

Huang, C., L. Sun, and R. Yang. 1973. Age, growth and population structure of Indian yellowfin tuna. Journal of the Fisheries Society of Taiwan 2(1):16-30.

Huang, C., and R. Yang. 1974. Age and growth of yellowfin tuna in the waters around the southern part of Taiwan. Journal of the Fisheries Society of Taiwan $\mathbf{3 ( 2 ) : 5 1 - 6 0 .}$

IOTC. 2012. Report of the Fourteenth Session of the IOTC Working Party on Tropical Tunas. IOTC Working Party of Tropical Tuna 14:88p.

Jusup, M., T. Klanjscek, H. Matsuda, and S. A. L. M. Kooijman. 2011. A full lifecycle bioenergetic model for bluefin tuna. PLoS ONE 6:e21903.

Kell, L., and P. Bromley. 2004. Implications for current management advice for North Sea plaice (Pleuronectes platessa L.): Part II. Increased biological realism in recruitment, growth, density-dependent sexual maturation and the impact of sexual dimorphism and fishery discards. Journal of Sea Research 51:301-312.

Langley, A., M. Herrera, and J. Million. 2012. Stock assessment of yellowfin tuna in the Indian Ocean using MULTIFAN-CL. Proceedings of the Fourteenth session of the IOTC Working Party on Tropical Tunas, Grand Baie, Mauritius, 24-29 October 2012, IOTC-2012-WPTT14-38:72p.

Langley, A., and J. Million. 2012. Determining an appropriate tag mixing period for the indian ocean yellowfin tuna stock assessment. Proceedings of the 
Fourteenth session of the IOTC Working Party on Tropical Tunas, Grand Baie, Mauritius, 24-29 October 2012, IOTC-2012-WPTT14-31:53p.

Laslett, G., J. Eveson, and T. Polacheck. 2002. A flexible maximum likelihood approach for fitting growth curves to tag-recapture data. Canadian Journal of Fisheries and Aquatic Sciences 59:976-986.

Le Guen, J., and G. Sakagawa. 1973. Apparent growth of yellowfin tuna from the Eastern Atlantic ocean. Fishery Bulletin 71:175-187.

Lehodey, P., and B. Leroy. 1999. Age and growth of yellowfin tuna (Thunnus albacares) from the western and central Pacific Ocean as indicated by daily growth increments and tagging data. Working Paper YFT-2, Meeting of the SCTB 12:21p.

Lessa, R., and P. Duarte-Neto. 2004. Age and growth of yellowfin tuna (Thunnus albacares) in the western equatorial Atlantic, using dorsal fin spines. Fisheries Research 69:157-170.

Li, T., C. Wang, and Y. Yeh. 1995. Age and growth of yellowfin tuna influenced by the human exploitation. Acta Oceanographica Taiwanica 34:43-60.

Longhurst, A., and D. Pauly. 1987. Ecology of tropical oceans, chapter Dynamic of tropical fish populations, pages 257-370 . Academic Press inc.

Lucena, F. M., and C. M. O'Brien. 2001. Effects of gear selectivity and different calculation methods on estimating growth parameters of bluefish, Pomatomus saltatrix (pisces: Pomatomidae), from southern brazil. Fishery Bulletin 99:432-444.

Lumineau, O. 2002. Study of the growth of yellowfin tuna (Thunnus albacares) in the Western Indian Ocean based on length frequency data. IOTC Proceedings 5:316-327.

Macdonald, P., and P. Green. 1988. User's guide to program MIX: An interactive program for fitting mixtures of distributions. 
Marcille, J., and B. Stéquert. 1976. Croissance des jeunes albacores Thunnus albacares et patudos, Thunnus obesus de la côte Nord-Ouest de Madagascar. Cahiers ORSTOM. Série Océanographie XIV:153-162.

Marsac, F. 1991. Preliminary study of the growth of yellowfin estimated from purse seine data in the Western Indian Ocean. IPTP Collective volume of working documents 6:35-39.

Marsac, F., and G. Lablache. 1985. Preliminary study of the growth of yellowfin estimated from purse seine data in the Western Indian Ocean. IPTP Collective volume of working documents TWS/85/31:91-110.

Miyabe, N. 1984. On the growth of yellowfin and bigeye tuna estimated from the tagging results. ICCAT Rec. Doc. Sci. 1:117-122.

Mohan, M., and K. Kunhikoya. 1985. Age and growth of Katsuwonus pelamis (Linnaeus) and Thunnus albacares (Bonnaterre) from Minicoy waters. Central Marine Fisheries Research Institute 36:143-216.

Moore, H. 1951. Estimation of age and growth of yellowfin tuna (Neothunnus macropterus ) in Hawaiian waters by size frequencies. Fishery Bulletin 52:132149.

Morize, E., J.-M. Munaron, J.-P. Hallier, and J. Million. 2008. Preliminary growth studies of yellowfin and bigeye tuna (Thunnus albacares and T. obesus) in the Indian Ocean by otolith analysis. IOTC Working Party on Tropical Tunas 30:13p.

Neilson, J. 1992. Sources of error in otolith microstructure examination In D.K. Stevenson and S.E. Campana, Otolith microstructure examination and analysis. Canadian Special Publication Fisheries Aquatic Science 117:115126.

Panfili, J., H. De Pontual, H. Troadec, and P. Wright. 2002. Manual of Fish Sclerochronology. Coédition Ifremer-IRD. 
Panfili, J., J. Tomas, and B. Morales-Nin. 2009. Otolith microstructure in tropical fish. in Tropical fish otoliths: information for assessment, management and ecology, Methods and Technologies in Fish Biology and Fisheries Volume 11: 212-248. Green B.S. et al. [Ed.].

Pannella, G. 1971. Fish otoliths: daily growth layers and periodical patterns. Science 173:1124-1127.

Pauly, D., and G. Morgan. 1987. Length-based methods in fishery research. ICLARM Conference Proceedings 13.

R Development Core Team. 2010. R: A Language and Environment for Statistical Computing. R Foundation for Statistical Computing, Vienna, Austria. ISBN 3-900051-07-0. http://www.R-project.org/

Restrepo, V., G. Diaz, J. Walter, J. Neilson, S. Campana, D. Secor, and R. Wingate. 2010. Updated estimate of the growth curve of Western Atlantic bluefin tuna. Aquatic Living Resources 23:335-342.

Rivot, E., E. Prévost, E. Parent, and J. L. Baglinière. 2004. A bayesian statespace modelling framework for fitting a salmon stage-structured population dynamic model to multiple time series of field data. Ecological Modelling 179:463-485.

Roa-Ureta, R. H. 2010. A likelihood-based model of fish growth with multiple length frequency data. Journal of Agricultural, Biological, and Environmental Statistics 15:416-429.

Romanov, E., and L. Korotkova. 1988. Age and growth rates of yellowfin tuna Thunnus albacares (Bonnaterre 1788) (Pisces, Scombridae) in the northwestern part of the Indian Ocean, determined by counting the rings of vertebrae. FAO/IPTP Collection Volume of Working Documents 3:68-73.

Sardenne, F., E. Dortel, G. Le Croizier, J. Million, M. Labonne, B. Leroy, N. Bodin, and E. Chassot. this issue. Aging tropical tunas from otolith mi- 
crostructures: Insights from the Indian Ocean Tuna Tagging Program. Fisheries Research .

Schnute, J., and D. Fournier. 1980. A new approach to length-frequency analysis: growth structure. Canadian Journal of Fisheries and Aquatic Sciences 37:1337-1351.

Secor, D., J. Dean, and E. Laban. 1991. Manual for otolith removal and preparation for microstructural examination.

Shuford, R., J. Dean, B. Stéquert, and E. Morize. 2007. Age and growth of yellowfin tuna in the Atlantic Ocean. ICCAT Collection Volume of Scientific Papers 60:330-341.

Spiegelhalter, D., A. Thomas, N. Best, and D. Lunn. 2011. OpenBUGS version 3.2.1 user manual.

Stéquert, B. 1995. Détermination de l'âge des thons tropicaux à partir de leurs otolithes: exemple du Yellowfin (Thunnus albacares). Document Technique du Centre ORSTOM de Brest 76:1-31.

Stéquert, B., J. Panfili, and J. Dean. 1996. Age and growth of yellowfin tuna, Thunnus albacares, from the western indian ocean, based on otolith microstructure. Fishery Bulletin 94:124-134.

Stéquert, B., J. Rodriguez, B. Cuisset, and F. Le Menn. 2001. Gonadosomatic index and seasonal variations of plasma sex steroids in skipjack tuna (Katsuwonus pelamis) and yellowfin tuna (Thunnus albacares) from the Western Indian Ocean. Aquatic Living Resources 14:313-318.

Sun, C.-L., N.-J. Su, and S.-Z. Yeh. 2003. Estimation of growth parameters and age composition for yellowfin tuna, Thunnus albacares, in the western pacific using the length-based MULTIFAN method. Working Paper YFT-5, Meeting of the SCTB 16:15p. 
Taylor, N. G., C. J. Walters, and S. J. Martell. 2005. A new likelihood for simultaneously estimating von bertalanffy growth parameters, gear selectivity, and natural and fishing mortality. Canadian Journal of Fisheries and Aquatic Sciences 62:215-223.

Viera, A. 2005. Study of the growth of yellowfin tuna (Thunnus albacares) in the Indian Ocean based on length-frequency data from 2000 to 2004. in Presented at the Seventh Session of the IOTC Working Party on Tropical Tunas, 18-22 July 2005, Phuket, Thailand, volume IOTC-2005-WPTT-32, page $17 \mathrm{p}$. IOTC, Phuket, Thailand, p. 17.

von Bertalanffy, L. 1938. A quantitative theory of organic growth (Inquiries on growth laws. II). Human Biology 10:181-213.

Wang, Y.-G. 1998. Growth curves with explanatory variables and estimation of the effect of tagging. Australian and New Zealand Journal of Statistics 40:299-304.

Wankowski, J. 1981. Estimated growth of surface-schooling skipjack tuna, Katsuwonus pelamis, and yellowfin tuna, Thunnus albacares, from the Papua New Guinea region. Fishery Bulletin 79:517-545.

West, G. B., J. H. Brown, and B. J. Enquist. 2001. A general model for ontogenetic growth. Nature 413:628-631.

White, T. 1982. The Philippine tuna fishery and aspects of the population dynamics of tunas in Philippine waters. IPTP Collective Volume of Working Documents SCS/82/WP/114:1-64.

Yabuta, Y., and M. Yukinawa. 1957. Age and growth of yellowfin tuna (Neothunnus macropterus) in Japanese waters by size frequencies. Report of Nankai Regional Fisheries Research Laboratory 5:127-133.

Yabuta, Y., and M. Yukinawa. 1959. Growth and age of the yellowfin tuna (Neothunnus macropterus) in the equatorial Pacific. Report of Nankai Regional Fisheries Research Laboratory 11:77-87. 
Yabuta, Y., M. Yukinawa, and Y. Warashina. 1960. Growth and age of yellowfin tuna 2: Age determination (scale method). Report of Nankai Regional Fisheries Research Laboratory 12:63-74.

Yang, R., Y. Nose, and Y. Hiyama. 1969. A comparative study on the age and growth of yellowfin tunas from the Pacific and Atlantic Oceans. Far Seas Fisheries Research Laboratory Bulletin 2:1-21.

Yesaki, M. 1983. Observations on the biology of yellowfin (Thunnus albacares) and skipjack (Katsuwonus pelamis) tunas in Philippine waters. IPTP Collective Volume of Working Documents SCS/82/WP/119:1-66.

Zhu, G., L. Xu, X. Dai, and W. Liu. 2011. Growth and mortality rates of yellowfin tuna, Thunnus albacares (Perciformes: Scombridae), in the eastern and central Pacific Ocean. Zoologia 28:199-206.

Zhu, G., L. Xu, Y. Zhou, and L. Song. 2008. Reproductive biology of yellowfin tuna T. albacares in the West-Central Indian Ocean. Journal of Ocean University of China 7:327-332.

Zudaire, I., H. Murua, M. Grande, and N. Bodin. 2013. Reproductive potential of the yellowfin tuna (Thunnus albacares) in the western indian ocean. Fishery Bulletin 111:252-264.

\section{Liste of appendices}

Appendix A. Literature review of growth parameters of yellowfin

Appendix B. OpenBugs code for the integrated growth model

Appendix C. Matrices of correlation and covariance of somatic growth models 

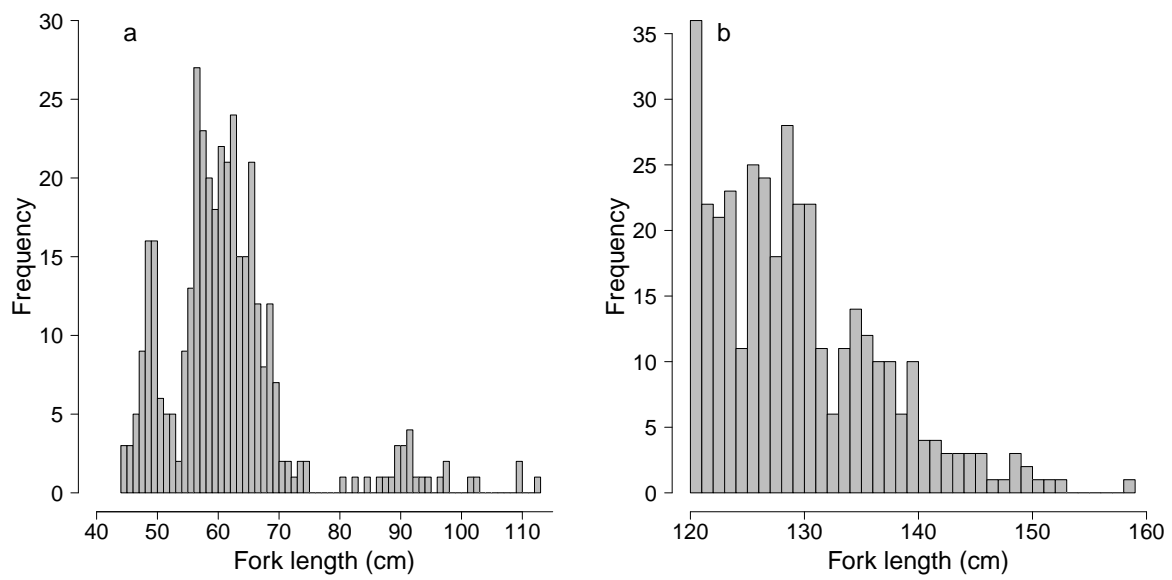

Figure 1: Distribution of size at (a) tagging and (b) recovery for the 373 tunas used in the mark-recapture component of the integrated growth model of the Indian Ocean yellowfin tuna 


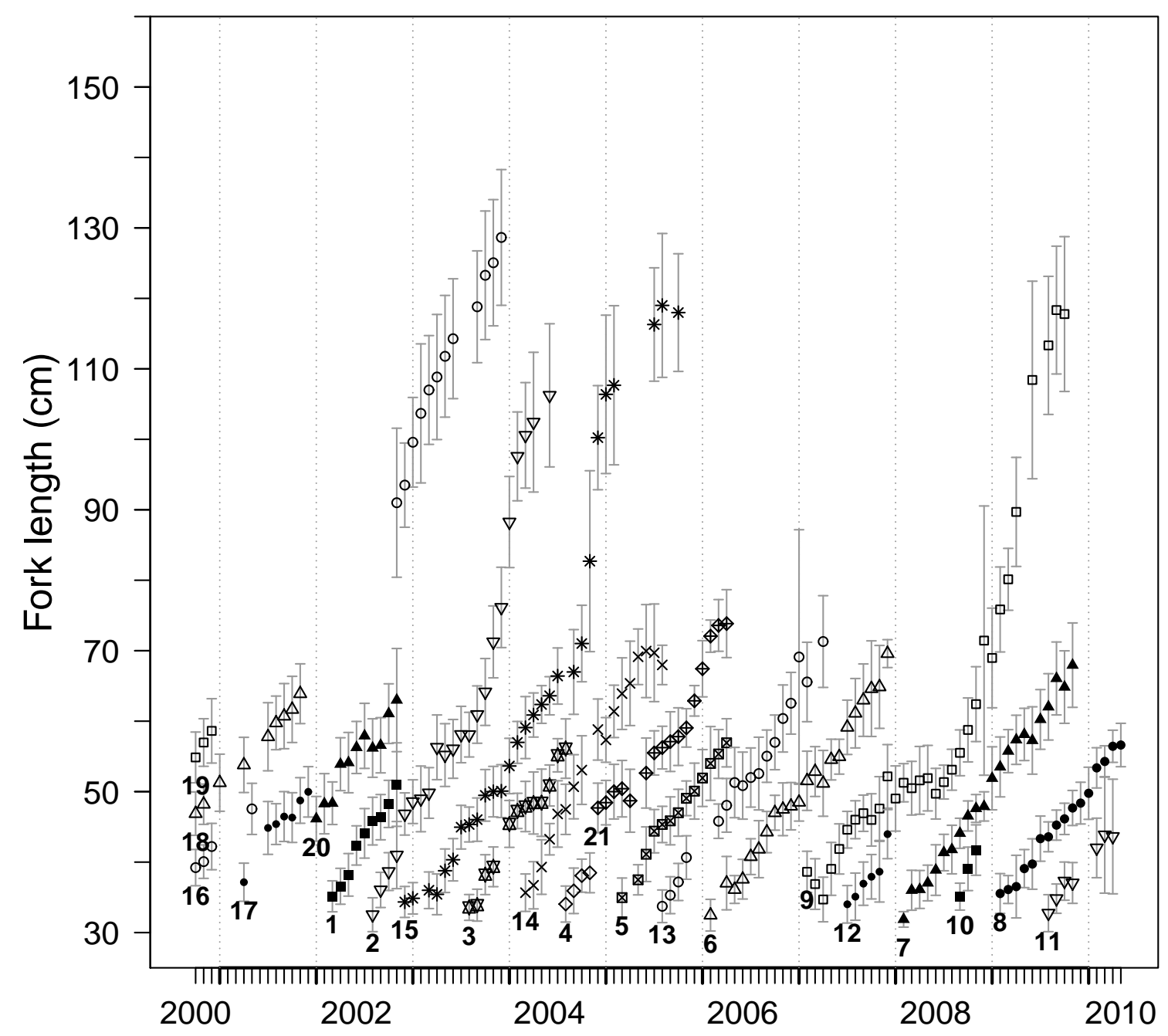

Figure 2: Monthly length modes and cohorts identified from length-frequency purse seine data. Each cohort is distinguished by a different symbol and is numbered. The symbols and the circles represent the mode values estimated from fitting a mixture of normal distributions to the length-frequency data. Vertical lines indicate standard deviations 

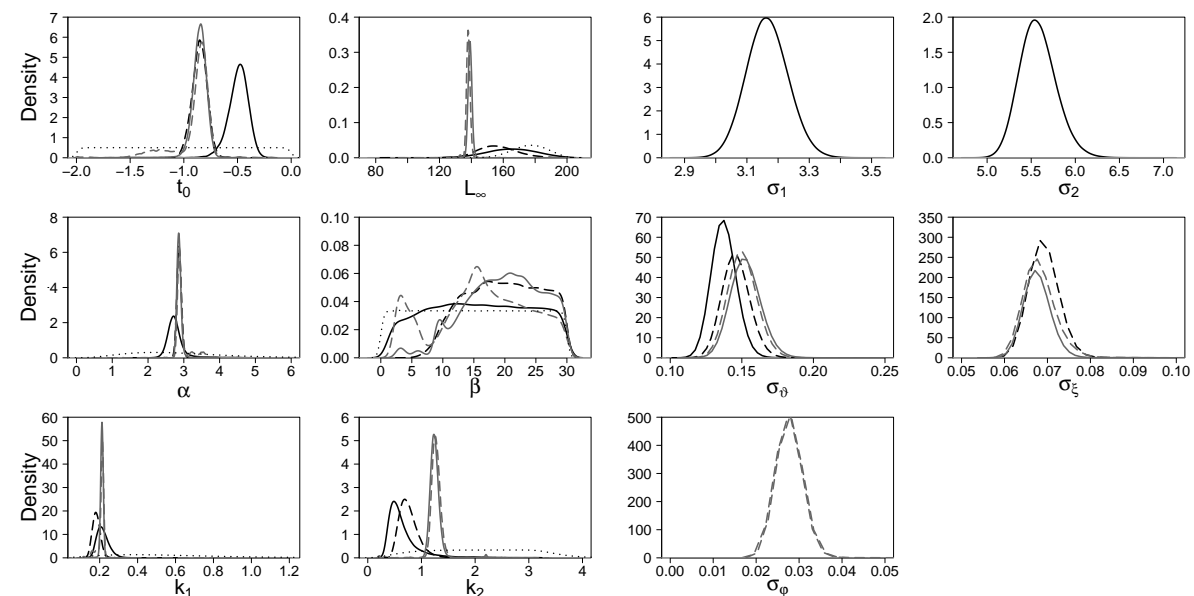

Figure 3: Comparison of the prior distributions (grey dotted line) with the marginal posterior distributions of the four growth parameters sets as estimated from the model 1, which was fitted to the otolith data (solid black line), model 2, which was fitted to both the otolith and length-frequency data (dotted black line), and model 3, which was fitted to the otolith, lengthfrequency, and mark-recapture data based on a gamma (grey solid line) and a log-normal (grey dashed line) distribution for the prior of ages-at-tagging. See Table 1 for notation definitions 

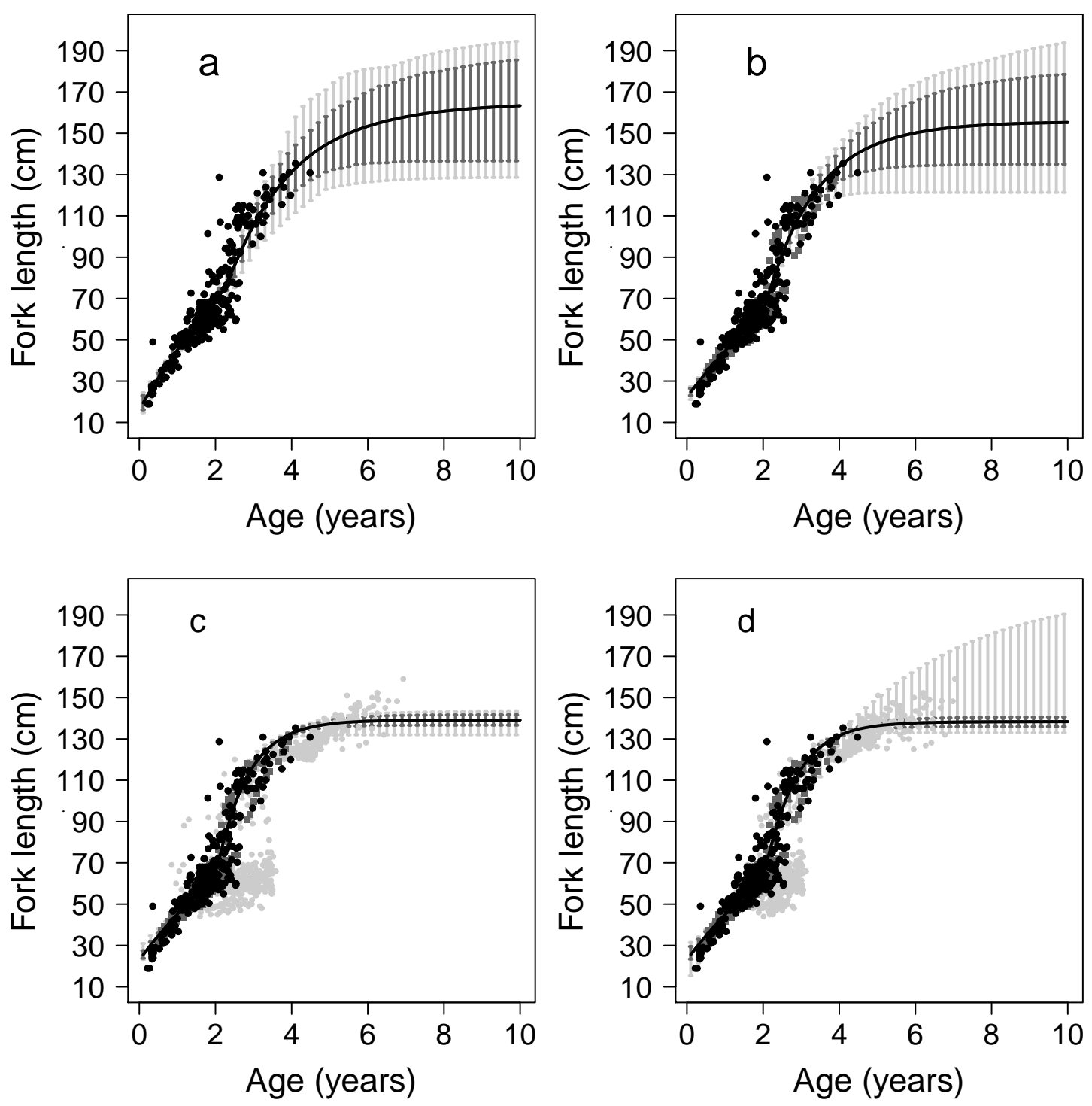

Figure 4: Growth curves of Indian Ocean yellowfin as estimated from (a) model 1 fitted to otolith data (black points), (b) model 2 fitted to otolith and length-frequency data (dark grey squares), (c) model 3 fitted to otolith, length-frequency and mark-recapture data (light grey points) based on a gamma distribution for the prior of ages-at-tagging and (d) model 3 fitted to otolith, length-frequency and mark-recapture data based on a log-normal distribution for the prior of ages-at-tagging. Mark recapture data are represented by the means of the marginal posterior estimates of ages at-tagging and recapture. The dark grey vertical lines correspond to the $95 \%$ Bayesian credibility interval and the light grey vertical lines to the predictive distribution defined by the minimal and maximal lengths predicted for each age 

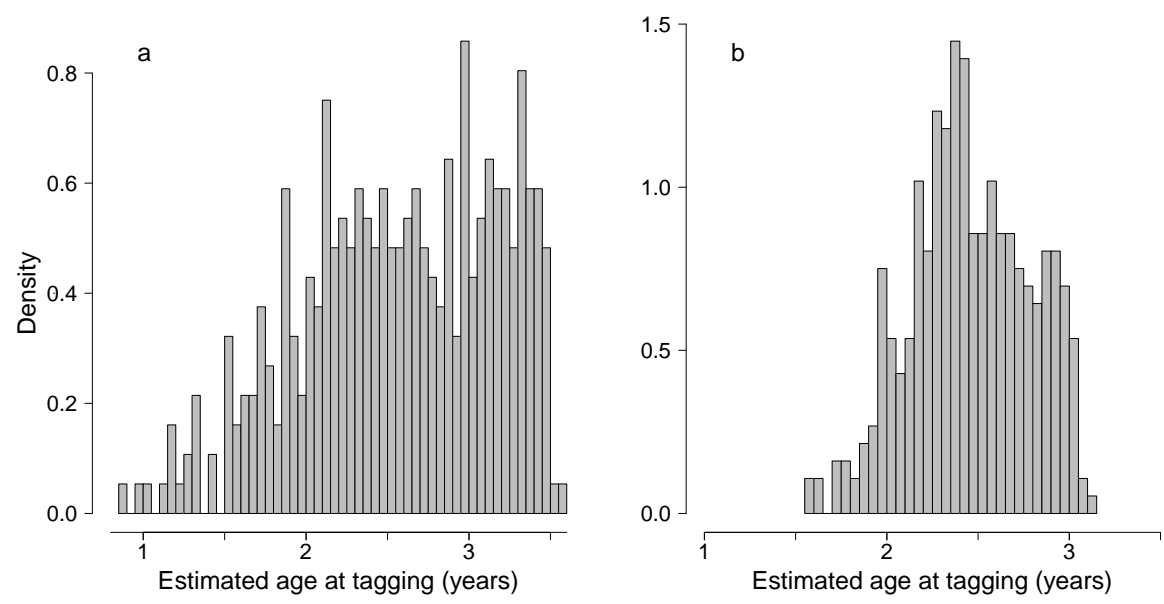

Figure 5: Density histograms of the marginal posterior distribution means of ages-at-tagging as estimated from model 3 with (a) gamma and (b) log-normal distribution for the prior of ages-at-tagging. Solid grey line indicates the overall age-at-tagging prior distribution 


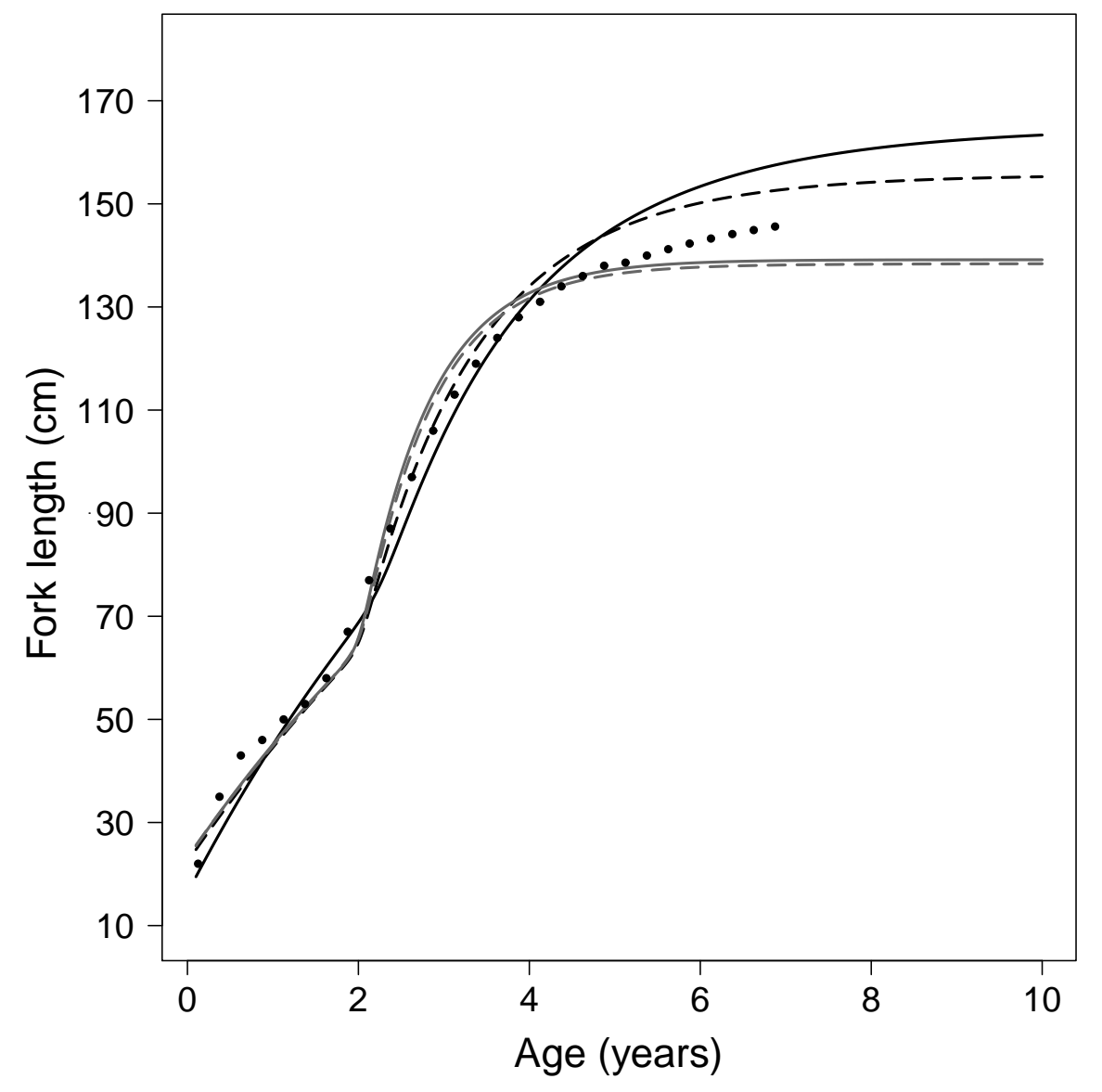

Figure 6: Growth curves of Indian Ocean yellowfin as estimated from model 1 fitted to otolith data (solid black line), model 2 fitted to otolith and length-frequency data (dashed black line), model 3 fitted to otolith, length-frequency and mark-recapture data based on a gamma (solid grey line) and a log-normal (dashed grey line) distribution for the prior of ages-attagging. Dotted black points represent the growth curve used in the most recent yellowfin stock assessment (IOTC, 2012) 
Table captions

\section{List of Tables}

1 Parameters and variables used in the aging and growth models; $m$ : microincrements; OTC $=$ oxytetracycline $\ldots \ldots \ldots . . .43$

2 Prior probability distributions used for estimating aging and growth parameters. The two parameters used for the $\Gamma$ distribution are respectively the shape and the scale. See Table 1 for notation definitions . . . . . . . . . . . . . . . . . . . 44

3 Main features of the marginal posterior distributions of the growth parameters as estimated from model 1 fitted to otolith data and model 2 fitted to otolith and length-frequency data. See Table 1 for notation definitions . . . . . . . . . . . . . . . . . . 45

4 Main features of the marginal posterior distributions of the growth parameters as estimated from model 3 fitted to otolith, lengthfrequency and mark-recapture data based on a gamma and a lognormal distribution for the prior of ages-at-tagging. See Table 1 for notation definitions . . . . . . . . . . . . . . . 46

A1 Growth parameters of yellowfin available in the literature. $k=$ growth rate, $L_{\infty}=$ asymptotic length, $t_{0}=$ Age of fork length zero. F: female, M: male . . . . . . . . . . . . . . . . . . 48

D1 Matrix of correlation and covariance between growth parameters for model 1 which was fitted to the otolith data and model 2 which was fitted to both the otolith and length-frequency data; the numbers in bold correspond to the correlations. See Table 1 for notation definitions . . . . . . . . . . . . . . 60

D2 Matrix of correlation and covariance between growth parameters for model 3 which was fitted to the otolith, length-frequency and mark-recapture data based on a gamma and a log-normal distribution for the prior of ages-at-tagging. The numbers in bold correspond to the correlations. See Table 1 for notation definitions 61 
Table 1: Parameters and variables used in the aging and growth models; $m$ : microincrements; OTC $=$ oxytetracycline

\begin{tabular}{|c|c|c|c|}
\hline Notation & Definition & Unit & Equation \\
\hline \multicolumn{4}{|c|}{ Aging model } \\
\hline$T_{L}$ & Time-at-liberty, i.e. time between tagging and recapture & $\mathrm{d}$ & 1 \\
\hline$R$ & Daily deposition rate of increment in otolith & $\mathrm{m} \mathrm{d}^{-1}$ & $1,3,5$ \\
\hline$\eta$ & Reading error at the otolith edge & $\mathrm{m}$ & 1,5 \\
\hline$\sigma_{\eta}$ & Standard deviation of the distribution of $\eta$ & $\mathrm{m}$ & - \\
\hline$I_{M}$ & Number of increments between OTC mark and otolith edge & $\mathrm{m}$ & $1-2$ \\
\hline$p$ & Relative percentage of misread otolith increments & $\%$ & $2,4,6$ \\
\hline$A_{T}$ & Absolute age-at-tagging & $\mathrm{d}$ & 3 \\
\hline$\psi$ & Reading error at the otolith nucleus & $\mathrm{m}$ & 3,5 \\
\hline$\sigma_{\psi}$ & Standard deviation of the distribution of $\psi$ & $\mathrm{m}$ & - \\
\hline$I_{T}$ & Number of increments between nucleus and OTC mark & $\mathrm{m}$ & 3,4 \\
\hline$A_{R}$ & Absolute age-at-recapture & $\mathrm{d}$ & 5 \\
\hline$I_{R}$ & Number of increments between nucleus and otolith edge & $\mathrm{m}$ & 5,6 \\
\hline \multicolumn{4}{|c|}{ Somatic growth model } \\
\hline$F_{L}$ & Fish fork length & $\mathrm{cm}$ & $7,8,12$ \\
\hline$A$ & Absolute age of fish at tagging or recovery & $\mathrm{y}$ & $7,8,12$ \\
\hline$L_{\infty}$ & Asymptotic fork length & $\mathrm{cm}$ & $7,8,11,12$ \\
\hline$t_{0}$ & Age of fork length zero & $\mathrm{y}$ & $7,8,11,12$ \\
\hline$\alpha$ & Age relative to $t_{0}$ at which the change in growth occurs & $\mathrm{y}$ & $7,8,11,12$ \\
\hline$\beta$ & Transition rate between $k_{1}$ and $k_{2}$ & $y^{-1}$ & $7,8,11,12$ \\
\hline$k_{1}$ & Growth rate coefficient of first stanza & $\mathrm{y}^{-1}$ & $7,8,11,12$ \\
\hline$k_{2}$ & Growth rate coefficient of second stanza & $\mathrm{y}^{-1}$ & $7,8,11,12$ \\
\hline$\vartheta$ & Process error for otolith data & $\mathrm{cm}$ & 8 \\
\hline$\sigma_{\vartheta}$ & Standard deviation of the distribution of $\vartheta$ & $\mathrm{cm}$ & - \\
\hline$\varepsilon_{1}$ & Observation error in length measurement at tagging & $\mathrm{cm}$ & 8 \\
\hline$\varepsilon_{2}$ & Observation error in length measurement at recovery & $\mathrm{cm}$ & 8,12 \\
\hline$\Delta L^{*}$ & Difference between length measurements of two successive taggings & $\mathrm{cm}$ & 9 \\
\hline$\sigma_{1}$ & Standard deviation of the distribution of $\varepsilon_{1}$ & $\mathrm{~cm}$ & 9 \\
\hline$\Delta S^{*}$ & Difference between length measurements in fresh and frozen state & $\mathrm{cm}$ & 10 \\
\hline$\varepsilon_{f}$ & Observation error in length measurement due to freezing & $\mathrm{cm}$ & - \\
\hline$\sigma_{f}$ & Standard deviation of the distribution of $\varepsilon_{f}$ & $\mathrm{~cm}$ & 10 \\
\hline$\mu_{c d}$ & Modal length of cohort $c$ at month $d$ in length-frequency data & $\mathrm{cm}$ & 11 \\
\hline$a_{c d}$ & Absolute age of cohort $c$ at month $d$ in length-frequency data & $\mathrm{y}$ & 11 \\
\hline$\xi$ & Process error for length-frequency data & $\mathrm{cm}$ & 11 \\
\hline$\sigma_{\xi}$ & Standard deviation of the distribution of the $\xi$ & $\mathrm{cm}$ & - \\
\hline$\varphi$ & Process error for mark-recapture data & $\mathrm{cm}$ & 12 \\
\hline$\sigma_{\varphi}$ & Standard deviation of the distribution of $\varphi$ & $\mathrm{cm}$ & - \\
\hline
\end{tabular}


Table 2: Prior probability distributions used for estimating aging and growth parameters. The two parameters used for the $\Gamma$ distribution are respectively the shape and the scale. See Table 1 for notation definitions

\begin{tabular}{ll}
\hline Parameter & Prior distribution \\
\hline \multicolumn{2}{c}{ Aging model } \\
$\eta$ & $2 \cdot R^{\prime}$ with $R^{\prime} \sim \mathcal{B}$ eta $(1,1)$ \\
$p$ & $\mathcal{N}\left(0,4^{2}\right)$ \\
$\psi$ & $\mathcal{U}(0,0.5)$ \\
Somatic growth model \\
$L_{\infty}$ & $\mathcal{N}\left(0,3^{2}\right)$ \\
$k_{1}$ & $\Gamma(2.778,0.211)$ \\
$k_{2}$ & $\mathcal{G}_{1}+\kappa$ with $\kappa \sim \mathcal{U}(0,3)$ \\
$\alpha$ & $\Gamma(4,1)$ \\
$\beta$ & $\mathcal{U}(0,30)$ \\
$t_{0}$ & $\mathcal{U}(-2,0)$ \\
$A_{T}$ & $\Gamma(1.33,0.67)$ or $\log \mathcal{N}(\log (2), 3.7)$ \\
$\sigma_{1}$ & $\operatorname{Inv} \Gamma(0.01,0.01)$ \\
$\sigma_{f}$ & $\operatorname{Inv} \Gamma(0.01,0.01)$ \\
$\sigma_{\vartheta}$ & $\operatorname{Inv} \Gamma(0.01,0.01)$ \\
$\sigma_{\xi}$ & $\operatorname{Inv} \Gamma(0.01,0.01)$ \\
$\sigma_{\varphi}$ & $\operatorname{Inv} \Gamma(0.01,0.01)$ \\
\hline &
\end{tabular}


Table 3: Main features of the marginal posterior distributions of the growth parameters as estimated from model 1 fitted to otolith data and model 2 fitted to otolith and length-frequency data. See Table 1 for notation definitions

\begin{tabular}{|c|c|c|c|c|c|c|c|c|c|c|}
\hline \multirow{3}{*}{ Parameters } & \multicolumn{5}{|c|}{ Model 1} & \multicolumn{5}{|c|}{ Model 2} \\
\hline & \multirow{2}{*}{ Mode } & \multirow{2}{*}{ Mean } & \multirow{2}{*}{ Std.dev. } & \multicolumn{2}{|c|}{ Posterior quantiles } & \multirow{2}{*}{ Mode } & \multirow{2}{*}{ Mean } & \multirow{2}{*}{ Std.dev. } & \multicolumn{2}{|c|}{ Posterior quantiles } \\
\hline & & & & $2.5 \%$ & $97.5 \%$ & & & & $2.5 \%$ & $97.5 \%$ \\
\hline$L_{\infty}$ & 167.907 & 165.07 & 14.135 & 136.697 & 190.21 & 151.327 & 155.703 & 11.941 & 135.095 & 181.107 \\
\hline$t_{0}$ & -0.483 & -0.489 & 0.091 & -0.691 & -0.338 & -0.845 & -0.851 & 0.069 & -0.987 & -0.72 \\
\hline$\alpha$ & 2.75 & 2.776 & 0.307 & 2.382 & 3.557 & 2.861 & 2.865 & 0.068 & 2.749 & 3.009 \\
\hline$\beta$ & 15.56 & 16.463 & 8.027 & 2.27 & 29.331 & 20.791 & 19.821 & 5.883 & 9.534 & 29.56 \\
\hline$k_{1}$ & 0.211 & 0.217 & 0.03 & 0.171 & 0.288 & 0.182 & 0.184 & 0.021 & 0.147 & 0.228 \\
\hline$k_{2}$ & 0.513 & 0.668 & 0.353 & 0.359 & 1.589 & 0.732 & 0.78 & 0.195 & 0.498 & 1.181 \\
\hline$\sigma_{\vartheta}$ & 0.136 & 0.138 & 0.009 & 0.122 & 0.157 & 0.145 & 0.146 & 0.009 & 0.129 & 0.165 \\
\hline$\sigma_{\xi}$ & - & - & - & - & - & 0.069 & 0.069 & 0.003 & 0.064 & 0.076 \\
\hline$\sigma_{1}$ & 3.168 & 3.168 & 0.066 & 3.045 & 3.301 & 3.163 & 3.167 & 0.067 & 3.039 & 3.303 \\
\hline$\sigma_{2}$ & 5.575 & 5.578 & 0.201 & 5.213 & 5.968 & 5.498 & 5.584 & 0.207 & 5.201 & 6.026 \\
\hline$\sigma_{f}$ & 2.378 & 2.41 & 0.192 & 2.06 & 2.794 & 2.371 & 2.417 & 0.196 & 2.089 & 2.858 \\
\hline
\end{tabular}


Table 4: Main features of the marginal posterior distributions of the growth parameters as estimated from model 3 fitted to otolith, length-frequency and mark-recapture data based on a gamma and a log-normal distribution for the prior of ages-at-tagging. See Table 1 for notation definitions

\begin{tabular}{|c|c|c|c|c|c|c|c|c|c|c|}
\hline \multirow{3}{*}{ Parameters } & \multicolumn{5}{|c|}{ Model 3 (Gamma distribution) } & \multicolumn{5}{|c|}{ Model 3 (Log-normal distribution) } \\
\hline & \multirow{2}{*}{ Mode } & \multirow{2}{*}{ Mean } & \multirow{2}{*}{ Std.dev. } & \multicolumn{2}{|c|}{ Posterior quantiles } & \multirow{2}{*}{ Mode } & \multirow{2}{*}{ Mean } & \multirow{2}{*}{ Std.dev. } & \multicolumn{2}{|c|}{ Posterior quantiles } \\
\hline & & & & $2.5 \%$ & $97.5 \%$ & & & & $2.5 \%$ & $97.5 \%$ \\
\hline$L_{\infty}$ & 138.84 & 139.163 & 1.381 & 136.69 & 141.71 & 138.084 & 138.447 & 4.308 & 136 & 140.6 \\
\hline$t_{0}$ & -0.843 & -0.86 & 0.085 & -0.996 & -0.746 & -0.842 & -0.902 & 0.178 & -1.407 & -0.737 \\
\hline$\alpha$ & 2.854 & 2.874 & 0.092 & 2.765 & 3.011 & 2.878 & 2.957 & 0.227 & 2.783 & 3.614 \\
\hline$\beta$ & 20.291 & 19.659 & 5.871 & 7.871 & 29.006 & 16.885 & 16.297 & 7.438 & 2.813 & 28.439 \\
\hline$k_{1}$ & 0.211 & 0.211 & 0.009 & 0.197 & 0.225 & 0.213 & 0.207 & 0.019 & 0.155 & 0.226 \\
\hline$k_{2}$ & 1.247 & 1.251 & 0.111 & 1.099 & 1.437 & 1.268 & 1.27 & 0.128 & 1.13 & 1.456 \\
\hline$\sigma_{\vartheta}$ & 0.15 & 0.152 & 0.011 & 0.132 & 0.175 & 0.15 & 0.15 & 0.011 & 0.131 & 0.173 \\
\hline$\sigma_{\xi}$ & 0.067 & 0.068 & 0.003 & 0.062 & 0.074 & 0.067 & 0.068 & 0.005 & 0.062 & 0.076 \\
\hline$\sigma_{\varphi}$ & 0.028 & 0.028 & 0.003 & 0.023 & 0.033 & 0.028 & 0.028 & 0.007 & 0.023 & 0.033 \\
\hline$\sigma_{1}$ & 5.542 & 5.584 & 0.212 & 5.23 & 6.058 & 3.164 & 3.165 & 0.068 & 3.038 & 3.298 \\
\hline$\sigma_{2}$ & 5.542 & 5.584 & 0.212 & 5.23 & 6.058 & 5.554 & 5.578 & 0.208 & 5.212 & 6.024 \\
\hline$\sigma_{f}$ & 2.363 & 2.419 & 0.201 & 2.062 & 2.88 & 2.357 & 2.413 & 0.196 & 2.07 & 2.835 \\
\hline
\end{tabular}


${ }_{946}$ Appendix A. Literature review of growth parameters of yellowfin 
Table A1: Growth parameters of yellowfin available in the literature. $k=$ growth rate, $L_{\infty}$ = asymptotic length, $t_{0}=$ Age of fork length zero. F: female, M: male

\begin{tabular}{|c|c|c|c|c|c|c|c|}
\hline Region & Data type & Model & FL range $(\mathrm{cm})$ & $\mathrm{k}\left(\mathrm{y}^{-1}\right)$ & $L_{\infty}(\mathrm{cm})$ & $t_{0}(\mathrm{y})$ & Reference \\
\hline \multirow{3}{*}{ Indian } & Otoliths & Von Bertalanffy & & 0.176 & 245.541 & 0.266 & Stéquert et al. (1996) \\
\hline & \multirow{2}{*}{ Length-frequency } & \multirow{2}{*}{ Gascuel Model } & \multirow{2}{*}{$30-135$} & 0.86 & 162.7 & & \multirow{2}{*}{ Viera (2005) } \\
\hline & & & & 0.828 & 163.411 & & \\
\hline \multirow{5}{*}{ Western Indian } & Otoliths & Von Bertalanffy & $60-20$ & 0.176 & 272.7 & -0.266 & Stéquert (1995) \\
\hline & \multirow{4}{*}{ Length-frequency } & \multirow{2}{*}{ Von Bertalanffy } & \multirow{2}{*}{$60-144$} & 0.88 & 154.77 & 1.16 & \multirow{4}{*}{ Lumineau (2002) } \\
\hline & & & & 0.8 & 150.9 & 1.7 & \\
\hline & & \multirow{2}{*}{ Gascuel model } & \multirow{2}{*}{$30-144$} & 2.25 & 136.34 & & \\
\hline & & & & 0.84 & 152.07 & & \\
\hline Minicoy waters & Length-frequency & Von Bertalanffy & $27-137$ & 0.32 & 145 & -0.34 & Mohan and Kunhikoya (1985) \\
\hline \multirow{7}{*}{ Atlantic } & Scales & Von Bertalanffy & & 0.278 & 222.8 & & Yang et al. (1969) \\
\hline & Dorsal spines & Von Bertalanffy & & 0.37 & 192.4 & -0.003 & Draganik and Pelczarski (1984) \\
\hline & \multirow{2}{*}{ Length-frequency } & \multirow{2}{*}{ Von Bertalanffy } & & 0.72 & 166.4 & & Fonteneau (1981) \\
\hline & & & & 0.5 & & 189 & Fonteneau (1981) \\
\hline & & Von Bertalanffy & & 0.56 & 183.9 & & Miyabe (1984) \\
\hline & Tagging & Vo P & & 0.411 & 198.08 & & Roul ot 1 (1001) \\
\hline & & Von Bertalantty & & 0.485 & 152.59 & & Bard et al. (1991) \\
\hline Western Atlantic & Dorsale spines & Von Bertalanffy & & 0.267 & 230.7 & -0.081 & Lessa and Duarte-Neto (2004) \\
\hline & & Von Bertalanffy & & 0.42 & 194.8 & & Le Guen and Sakagawa (1973) \\
\hline Fastern Atlantic & Jenotbefreouencr. & Von Bertalanffy & $63-170$ & 0.42 & 194.8 & -0.748 & \\
\hline Eastern Atlantic & Length-frequency & 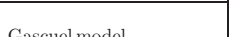 & $40-150$ & 1.195 & 158.5 & & Gascuel et al. (1992) \\
\hline & & Gascuel model & 41.4-147.4 & 1.495 & 152.6 & & \\
\hline Gulf of Guinea & Tagging & Von Bertalanffy & $65-180$ & 0.474 & 196.55 & 0.847 & Bard (1984) \\
\hline Culf of Cuine 20 & & & & 0.864 & 166.4 & 1.292 & \\
\hline Guil or Grimea & Tagging and Length-frequency & Von Bertalanffy & & 0.936 & 161.02 & & Fonteneau (1980) \\
\hline Dakar and Senegal & & & & 0.6 & 189 & & \\
\hline Venezuela & & & $65.88-160$ & 0.884 & 155.069 & 0.957 & \\
\hline Brasil & Length-frequency & Von Bertalanffy & $65-155$ & 0.43 & 184.12 & -0.079 & Gaertner and Pagavino (1991) \\
\hline Africa & & & $63.07-180$ & 0.566 & 189.04 & 1.193 & \\
\hline $\begin{array}{l}\text { Gulf of Guinea and North } \\
\text { Carolina }\end{array}$ & Otoliths & Von Bertalanffy & $30-179$ & 0.281 & 245.541 & 0.0423 & Shuford et al. (2007) \\
\hline Pacific & & & $70-148$ & 1.72 & 148 & 2 & Hennemuth (1961) \\
\hline Facinc & & & 72 to 149 & 1.888 & 149 & 2.294 & Davidoff (1963) \\
\hline & & & & 0.333 & 192.8 & & Huang and Yang (1974) \\
\hline & & & & 0.386 & 174.9 & & Huang et al. (1973) \\
\hline & & & & 0.129 & 178.6 & & Li et al. (1995) \\
\hline & Scales & Von Bertalanffy & M: $58-119$ & 0.276 & 202.1 & 0 & Le Guen and Sakagawa (1973) \\
\hline & & & F: $57-119$ & 0.372 & 174.9 & 0 & Le Guen and Sakagawa $(19 / 3)$ \\
\hline & & Von Bertalanffy & $70-140$ & 0.33 & 190.1 & 0 & Yabuta et al. (1960) \\
\hline & & Von Bertalanffy & $60-139$ & 0.36 & 195.2 & & Yang et al. (1969) \\
\hline Western Pacific & & Von Bertalanffy & & 0.39 & 199.6 & -0.177 & \\
\hline & Otoliths & & $45-70$ & 0.728 & 151.7 & -0.085 & Lehodey and Lerov (1999) \\
\hline & & Modified Von Bertalanffy & & M: 0.805 & 146.7 & -0.049 & \\
\hline & & & & F: 0.511 & 177.1 & -0.167 & \\
\hline & & & & 0.25 & 166 & & Hampton (2000) \\
\hline & To o t b fo & Von Bertalanffy & $50.8-164.4$ & 0.392 & 175 & 0.00306 & Sun et al. (2003) \\
\hline & Lengunirequency & & $80-150$ & 0.66 & 150 & 0.4 & Yabuta and Yukinawa (1959) \\
\hline & & Von Bertalanffy & $30-96$ & 0.292 & 180.9 & 0 & Wankowski (1981) \\
\hline Eastern Central Pacific & Length-frequency & Von Bertalanffy & $93-167$ & 0.52 & 175.9 & 0.19 & Zhu et al. (2011) \\
\hline & & & & 0.45 & 180 & & \\
\hline Western coast of America & Increment technic & Von Bertalanffy & $80-140$ & 0.66 & 167 & & Diaz (1963) \\
\hline & & & & 0.36 & 214 & & \\
\hline & & & & 0.7 & 166 & & \\
\hline Hawaiian waters & Weight modes & Von Bertalanffy & $70-120$ & 0.44 & 192 & 0.22 & Moore (1951) \\
\hline Japanese waters & Length-frequency & Von Bertalanffy & $30-150$ & 0.55 & 168 & 0.35 & Yabuta and Yukinawa (1957) \\
\hline & & & 20 & 0.29 & 179 & & \\
\hline & & Von Portalonf $f_{Y}$ & $20-00$ & 0.25 & 189 & & White (1082) \\
\hline Philinnine watere & Jenotb freournar & Von Bertalanfly & $20-60$ and $90-150$ & 0.43 & 182 & & White (1982) \\
\hline Fiminpine waters & Lengun-riequency & & $20-70$ & 0.2 & 169 & & \\
\hline & & Von Rortalonffy & $20-60$ ond 120180 & F: 0.32 & 173 & & Yesaki (1983) \\
\hline & & Von Bertalantty & $20-60$ and $120-160$ & M: 0.3 & 175 & & \\
\hline
\end{tabular}


Appendix B. Directed Acyclic Graphs for the models

A Directed Acyclic Graph (DAG) is a directed graph with no directed cycles. DAGs represent random quantities as nodes, which appears as ellipses linked by arrows indicating conditional dependencies. Random quantities are represented by open ellipses while observations are indicated by shaded ellipses. The arrows pointing from a node $\nu$ indicate the nodes under its direct influence, i.e., the children of $\nu(\operatorname{ch}(\nu))$. Arrows running into each node $\nu$ indicate the nodes which directly influence $\nu$, i.e., the parents of $\nu(\mathrm{pa}(\nu))$. Each node can be stochastic,

955 and then has its probability density function defined conditionally on its parents,

956 or logical when it is issued from a deterministic function of its parents (Rivot

${ }_{957}$ et al., 2004). The figures B1-B4 describe the DAGs for modeling the growth of

${ }_{958}$ Indian Ocean yellowfin tuna. 


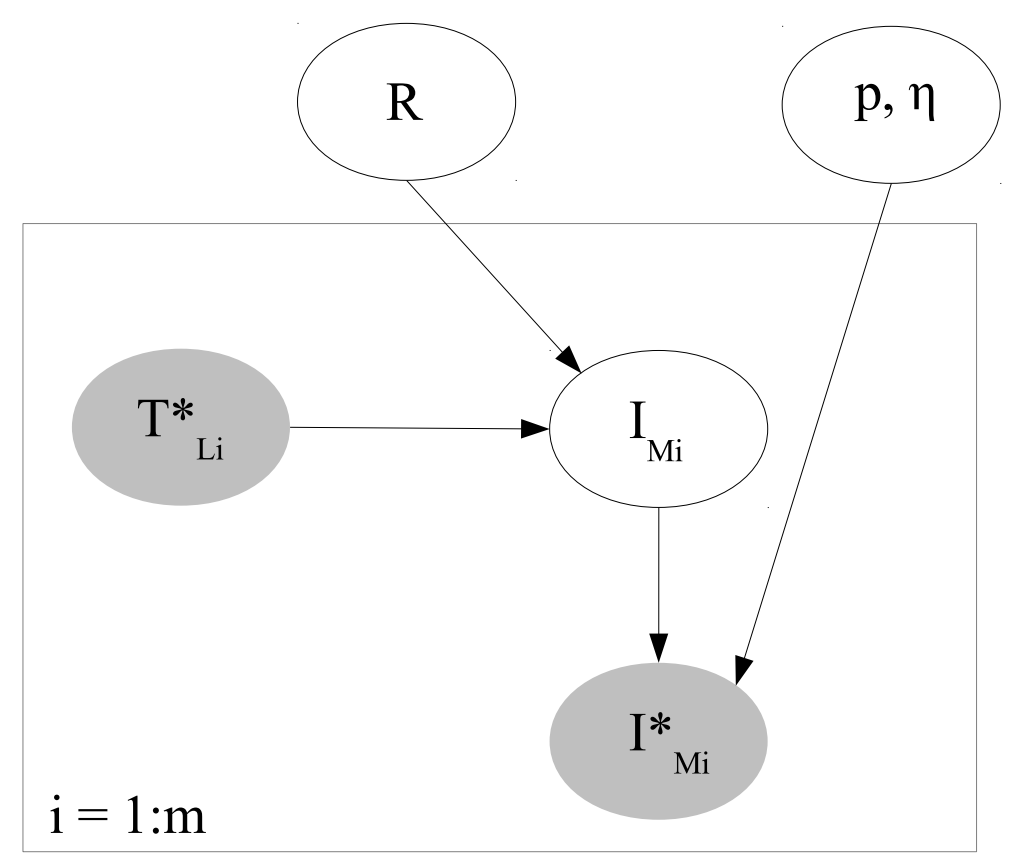

Figure B1: Directed Acyclic Graph representing the relationship between the microincrements counted between the oxytetracycline mark and otolith edge $\left(I_{M_{i}}^{*}\right)$ in yellowfin otoliths and time-at-liberty $\left(T_{L_{i}}^{*}\right)$ for fish i. $R=$ Daily deposition rate of increment in otolith; $p=$ Relative percentage of misread otolith increments; $\eta=$ Reading error at the otolith edge; $m=$ number of otoliths read 


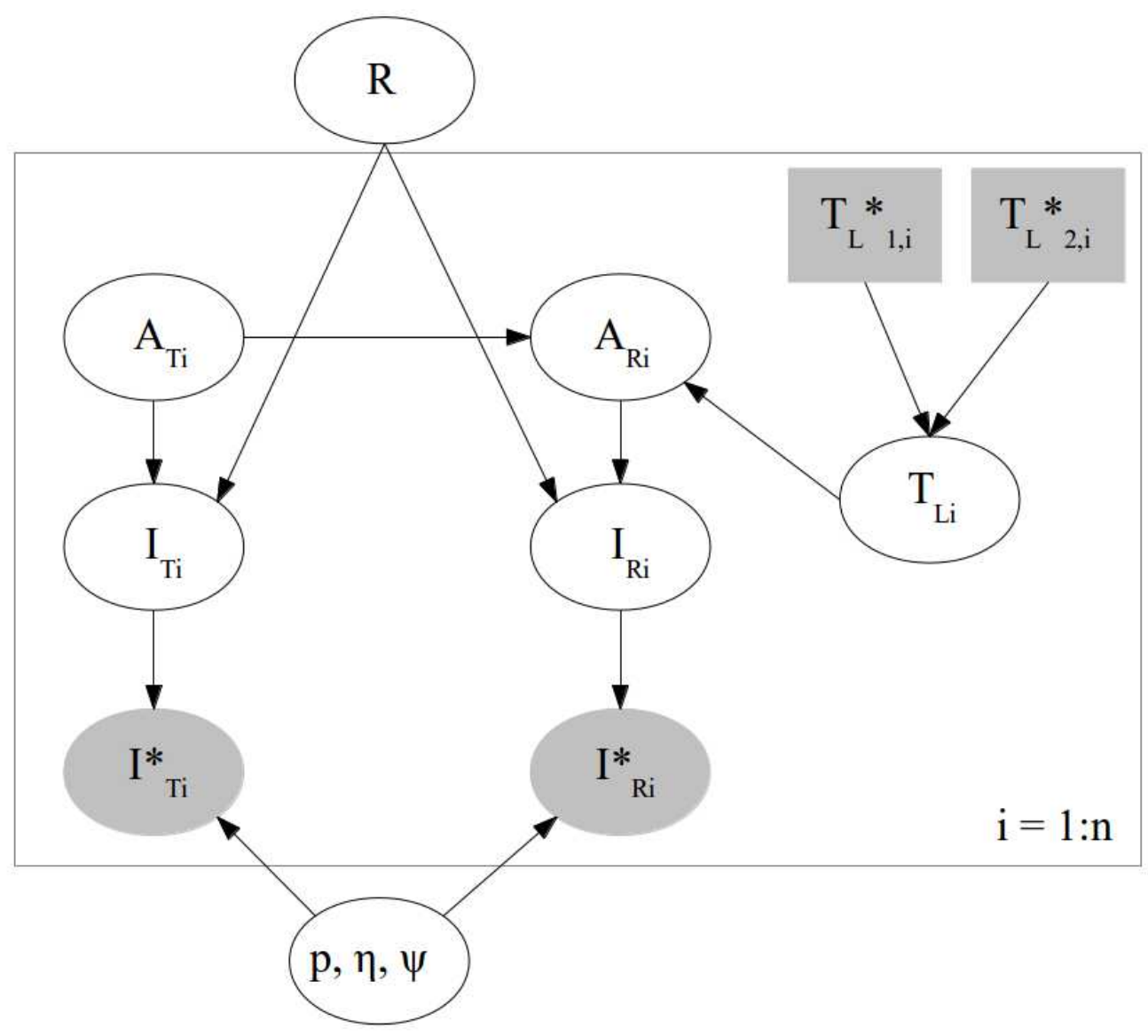

Figure B2: Directed Acyclic Graph representing the ageing error model linking the observations of microincrement counts at tagging $\left(I_{T_{i}}^{*}\right)$ and recovery $\left(I_{R_{i}}^{*}\right)$ to the ages-at-tagging $\left(A_{T_{i}}\right)$ and recapture $\left(A_{R_{i}}\right)$ for fish $i . T_{L_{i}}=$ Time-at-liberty; $T_{L_{1, i}}^{*}=$ Observation of minimum time-at-liberty; $T_{L_{2, i}}^{*}=$ Observation of maximum time-at-liberty; $R=$ Daily deposition rate of increment in otolith; $p=$ Relative percentage of misread otolith increments; $\eta=$ Reading error at the otolith edge; $\psi=$ Reading error at the otolith nucleus; $\mathrm{n}=$ number of fishes 


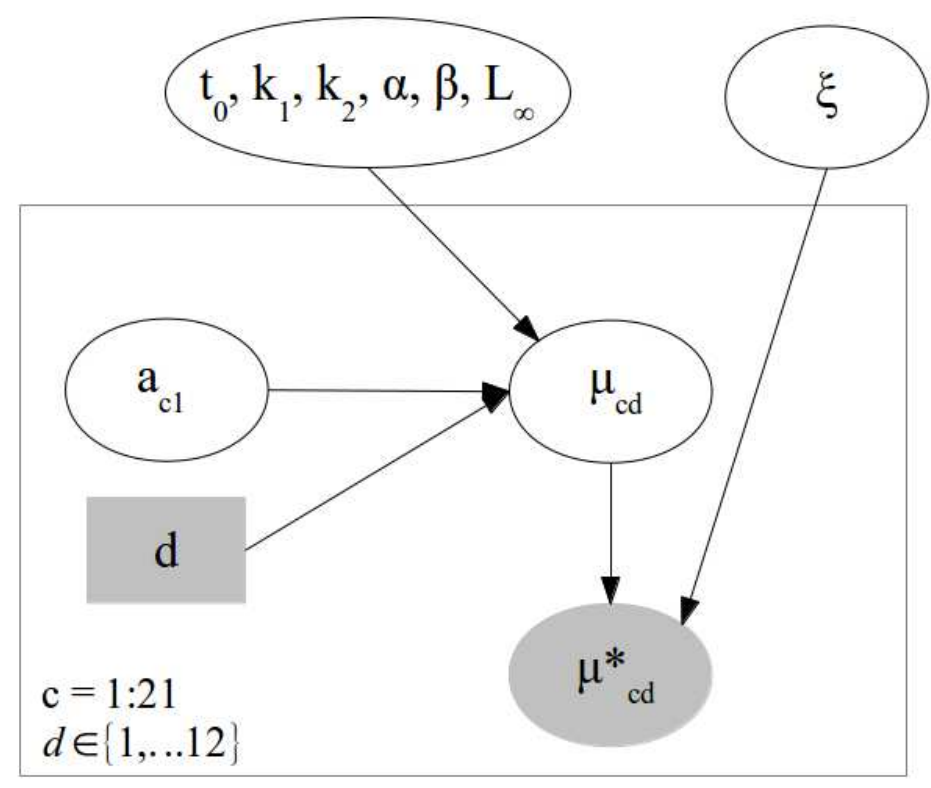

Figure B3: Directed Acyclic Graph representing the modal progression component of the growth model. $a_{c 1}=$ Absolute age of cohort $c$ for the first month; $d=$ Age of the cohort in months relative to the first month; $\mu_{c d}=$ Modal length of cohort $c$ at month $d ; \xi=$ Process error; $\left\{t_{0}, k_{1}, k_{2}, \alpha, \beta, L_{\infty}\right\}=$ vector of growth parameters defined in Table 1 


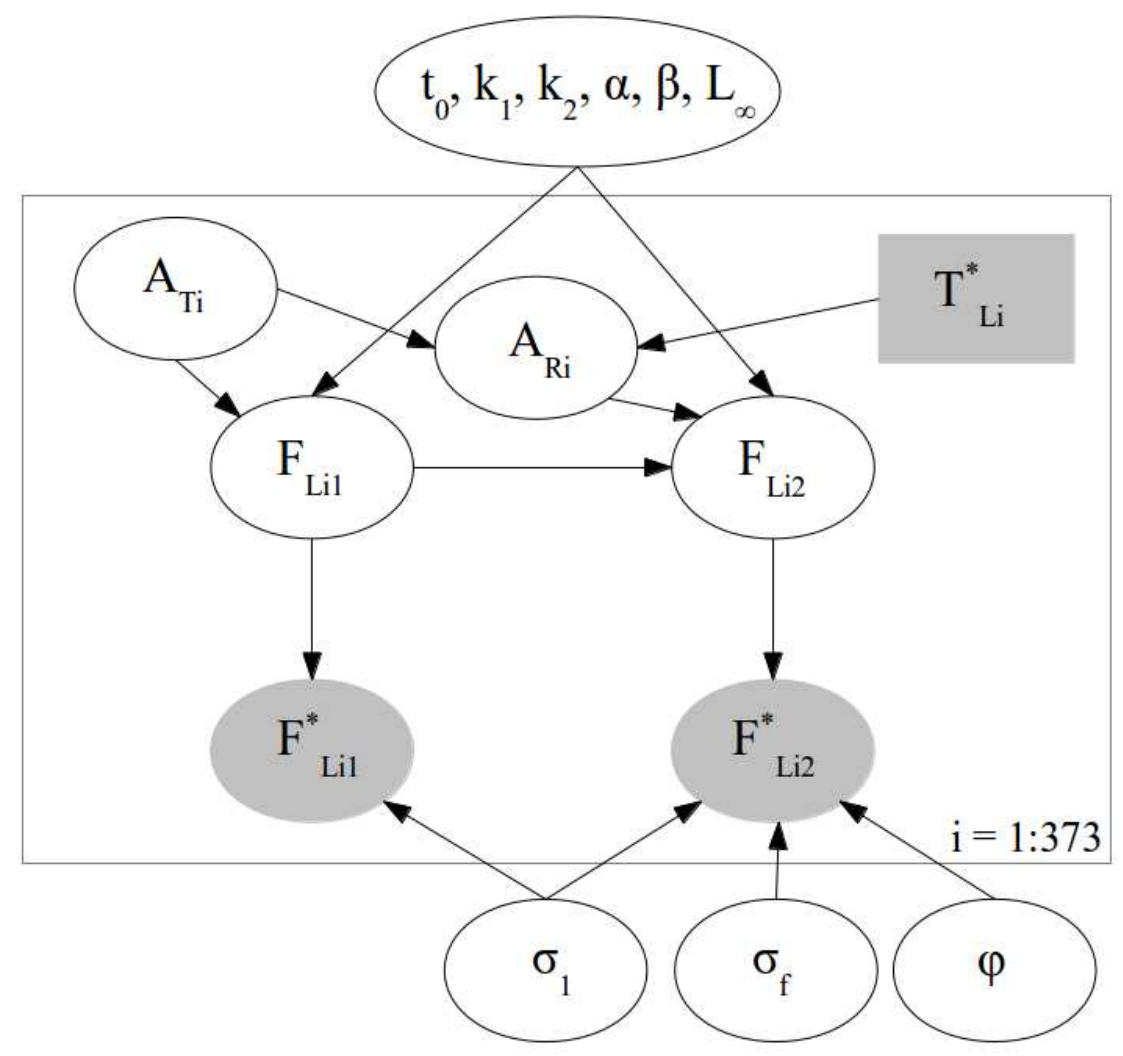

Figure B4: Directed Acyclic Graph representing the mark-recapture component of the growth model for fish $i . \quad F_{L}=$ Fork length; $A_{T_{i}}=$ age-at-tagging; $A_{R_{i}}=$ age-at-recapture; $T_{L_{i}}^{*}=$ Time-at-liberty; $\sigma_{1}=$ Standard deviation of the distribution of length measurement errors at-tagging ; $\sigma_{f}=$ Standard deviation of the distribution of length measurement errors due to freezing; $\varphi=$ Process error for mark-recapture data; $\left\{t 0, k_{1}, k_{2}, \alpha, \beta, L_{i} n f t y\right\}=$ vector of growth parameters defined in Table 1 
Appendix C. OpenBugs code for the integrated growth model 


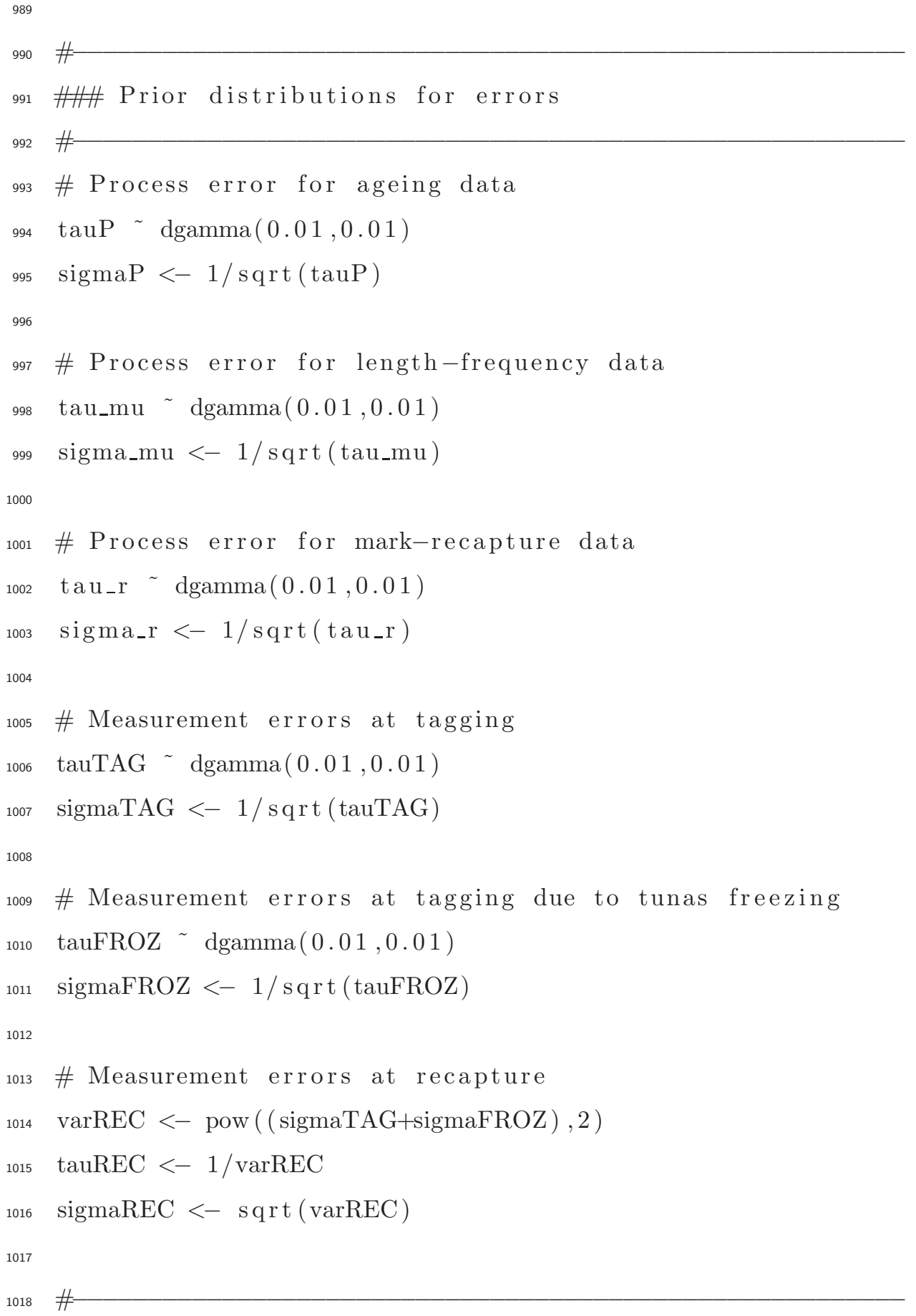


\#\# Estimating length measurement errors

\#\# Due to freezing fish

for $(i$ in $1: n \operatorname{Rec})\{$

DS [i ] $\operatorname{dnorm}(0$, tauFROZ $)$

\#-

\#\# Modeling growth

$\#$

\# Posterior distributions of length measurement errors not updated $\operatorname{tau} \mathrm{T}<-\operatorname{cut}(\operatorname{tauTAG})$

tauR $<-$ cut $($ tauREC $)$

$\#$

\#\# Ageing data

\# Fish caught once

for ( $\mathrm{i}$ in $1: n 1) \quad\{$

$\log _{-} L_{1} 1[\mathrm{i}]<-\log \left(\max \left(\operatorname{Linf} *\left(1-\exp \left(-\mathrm{k} 2 *\left(\mathrm{~A} 1 \_1 \_o b s[\mathrm{i}]-\mathrm{t} 0\right)\right)\right.\right.\right.$ *pow $\left(\left(\left(1+\exp \left(-\operatorname{beta} *\left(A 1 \_1 \_o b s[i]-\right.\right.\right.\right.\right.$ t0-alpha $\left.\left.)\right)\right) /(1+\exp ($ beta $*$ alpha $\left.))\right)$, $((\mathrm{k} 1-\mathrm{k} 2) /$ beta $))), 1))$ L1_1 [i ] dlnorm (Log_L1_1 [i ], tauP)

L1_1_obs [i ] $\operatorname{dnorm}\left(\mathrm{L}_{1} \_1[\mathrm{i}], \operatorname{tauT}\right)$ 
1072

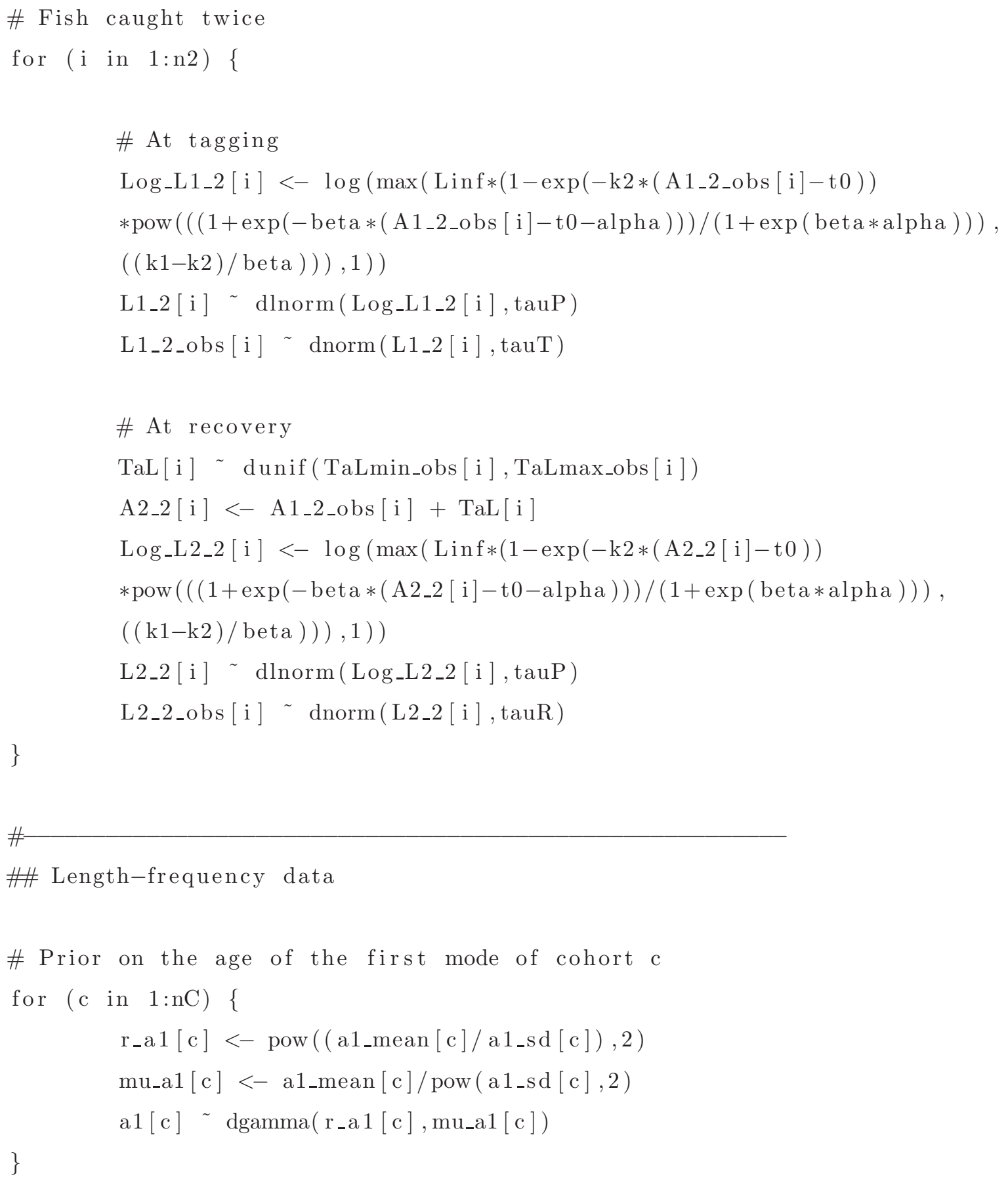
( 
1094

1098

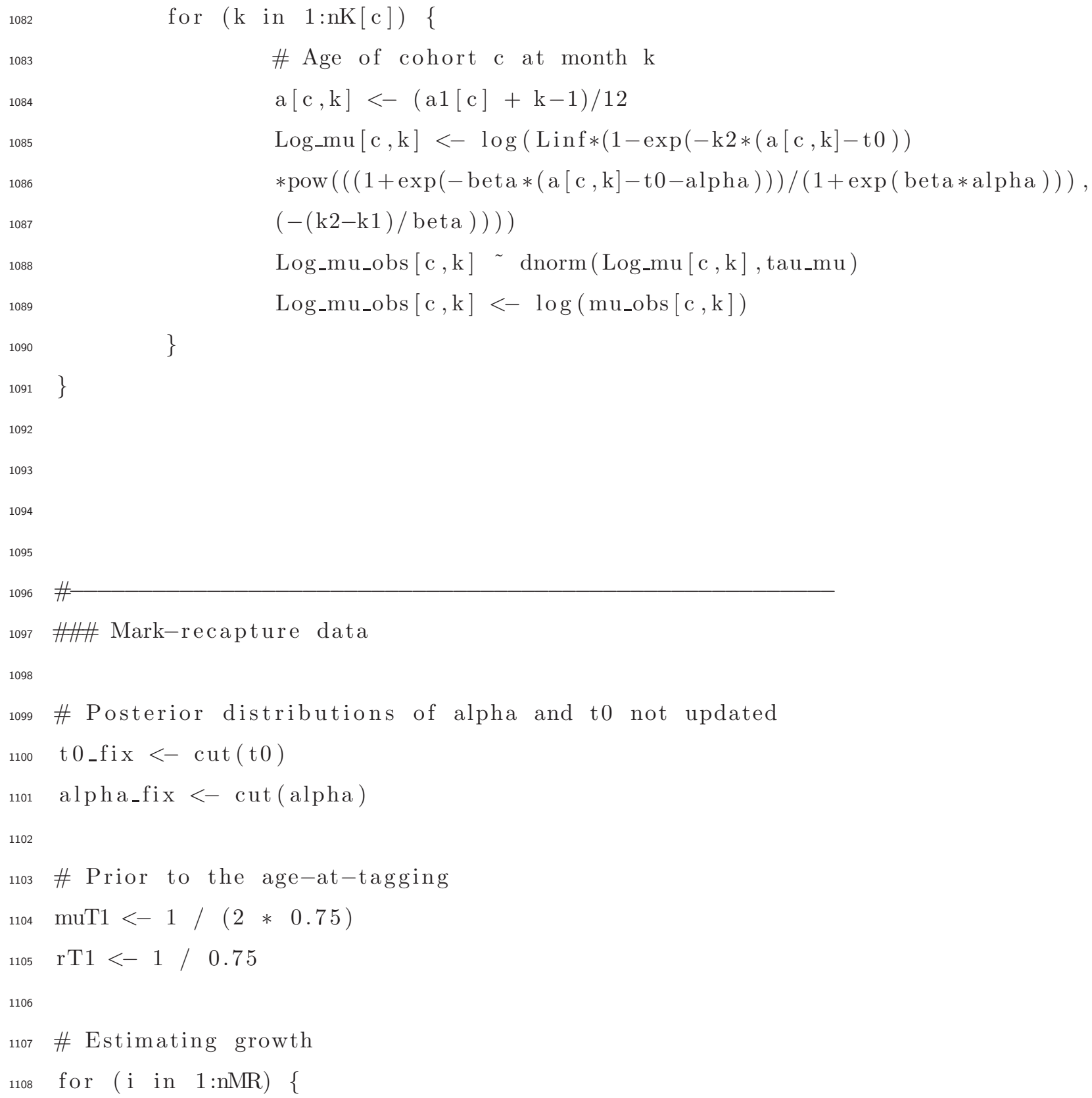

1107 \# Estimating growth

1108 for ( $\mathrm{i}$ in $1: \mathrm{nMR}$ ) \{ 


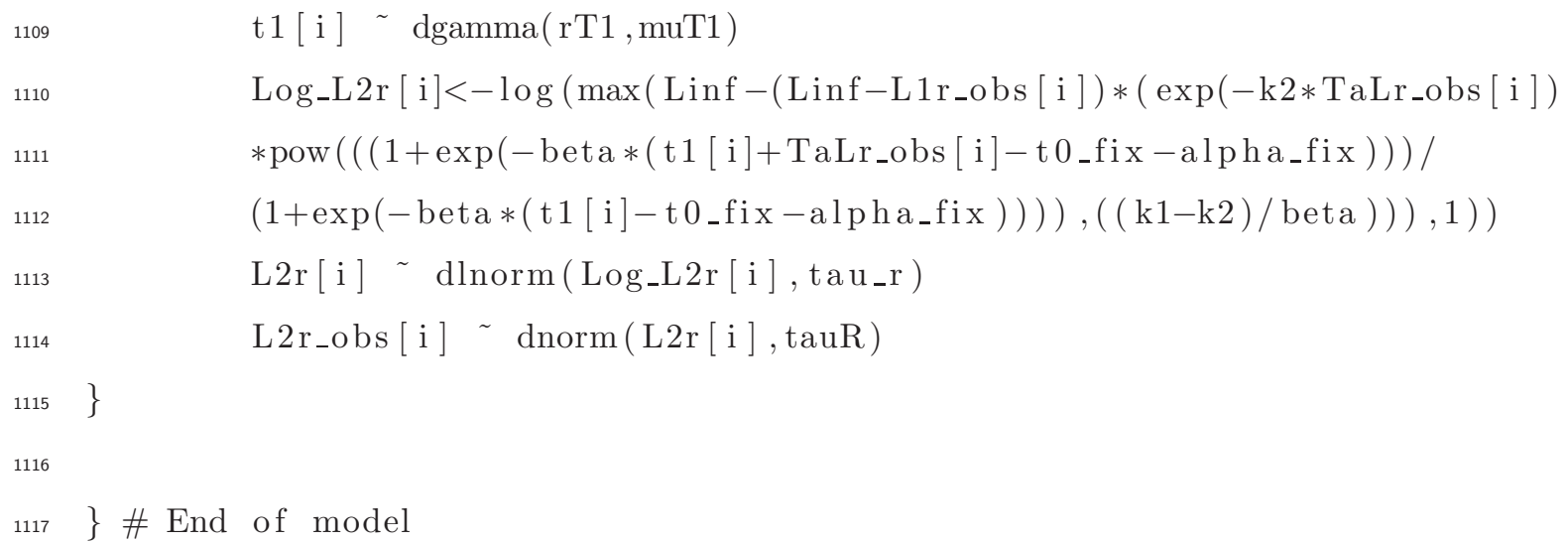


1118 Appendix D. Matrices of correlation and covariance for the somatic growth models

Table D1: Matrix of correlation and covariance between growth parameters for model 1 which was fitted to the otolith data and model 2 which was fitted to both the otolith and length-frequency data; the numbers in bold correspond to the correlations. See Table 1 for notation definitions

\begin{tabular}{l|llllll|llllll}
\hline & \multicolumn{7}{|c}{ Model 1} & \multicolumn{6}{c}{ Model 2} \\
& $L_{\infty}$ & $\alpha$ & $\beta$ & $k_{1}$ & $k_{2}$ & $t 0$ & $L_{\infty}$ & $\alpha$ & $\beta$ & $k_{1}$ & $k_{2}$ & $t 0$ \\
\hline$L_{\infty}$ & 234.184 & $\mathbf{0 . 0 4 2}$ & $\mathbf{0 . 0 5 2}$ & $\mathbf{- 0 . 8 8 6}$ & $\mathbf{- 0 . 6 0 0}$ & $\mathbf{- 0 . 2 6 8}$ & 147.225 & $\mathbf{0 . 1 5 6}$ & $\mathbf{0 . 1 3 8}$ & $\mathbf{- 0 . 9 4 1}$ & $\mathbf{- 0 . 8 4 9}$ & $\mathbf{- 0 . 4 1 5}$ \\
$\alpha$ & 0.235 & 0.131 & $\mathbf{- 0 . 3 5 2}$ & $\mathbf{- 0 . 1 4 4}$ & $\mathbf{0 . 4 7 8}$ & $\mathbf{- 0 . 2 1 0}$ & 0.139 & 0.005 & $\mathbf{- 0 . 2 3 2}$ & $\mathbf{- 0 . 3 6 2}$ & $\mathbf{0 . 0 5 3}$ & $\mathbf{- 0 . 7 0 2}$ \\
$\beta$ & 6.400 & -1.021 & 64.119 & $\mathbf{0 . 0 4 0}$ & $\mathbf{- 0 . 2 9 1}$ & $\mathbf{0 . 1 2 7}$ & 9.844 & -0.100 & 34.320 & $\mathbf{- 0 . 0 9 4}$ & $\mathbf{- 0 . 2 1 9}$ & $\mathbf{0 . 0 7 9}$ \\
$k_{1}$ & -0.451 & -0.002 & 0.011 & 0.001 & $\mathbf{0 . 5 3 4}$ & $\mathbf{0 . 6 1 2}$ & -0.240 & -0.001 & -0.012 & 0.000 & $\mathbf{0 . 8 4 7}$ & $\mathbf{0 . 6 4 3}$ \\
$k_{2}$ & -3.321 & 0.063 & -0.842 & 0.006 & 0.131 & $\mathbf{0 . 1 2 8}$ & -2.102 & 0.001 & -0.262 & 0.004 & 0.042 & $\mathbf{0 . 3 6 9}$ \\
$t_{0}$ & -0.391 & -0.007 & 0.097 & 0.002 & 0.004 & 0.009 & -0.362 & -0.004 & 0.033 & 0.001 & 0.005 & 0.004 \\
\hline
\end{tabular}


Table D2: Matrix of correlation and covariance between growth parameters for model 3 which was fitted to the otolith, length-frequency and markrecapture data based on a gamma and a log-normal distribution for the prior of ages-at-tagging. The numbers in bold correspond to the correlations. See Table 1 for notation definitions

\begin{tabular}{l|llllll|llllll}
\hline & \multicolumn{5}{|c|}{ Model 3 (Gamma distribution) } & \multicolumn{5}{c}{ Model 3 (Log-normal distribution) } \\
& $L_{\infty}$ & $\alpha$ & $\beta$ & $k_{1}$ & $k_{2}$ & $t 0$ & $L_{\infty}$ & $\alpha$ & $\beta$ & $k_{1}$ & $k_{2}$ & $t 0$ \\
\hline$L_{\infty}$ & 1.981 & $\mathbf{- 0 . 0 9 8}$ & $\mathbf{0 . 1 4 2}$ & $\mathbf{- 0 . 3 7 2}$ & $\mathbf{- 0 . 8 6 8}$ & $\mathbf{- 0 . 0 7 0}$ & 30.226 & $\mathbf{- 0 . 3 7 9}$ & $\mathbf{- 0 . 1 3 1}$ & $\mathbf{- 0 . 5 7 3}$ & $\mathbf{- 0 . 7 1 1}$ & $\mathbf{- 0 . 1 4 6}$ \\
$\alpha$ & -0.013 & 0.009 & $\mathbf{- 0 . 4 4 4}$ & $\mathbf{- 0 . 7 8 7}$ & $\mathbf{0 . 2 2 9}$ & $\mathbf{- 0 . 8 8 9}$ & -0.508 & 0.059 & $\mathbf{- 0 . 5 5 8}$ & $\mathbf{- 0 . 4 2 1}$ & $\mathbf{0 . 3 7 9}$ & $\mathbf{- 0 . 7 7 0}$ \\
$\beta$ & 1.201 & -0.248 & 36.179 & $\mathbf{0 . 2 8 2}$ & $\mathbf{- 0 . 2 3 1}$ & $\mathbf{0 . 3 1 2}$ & -5.397 & -1.023 & 56.531 & $\mathbf{0 . 5 7 6}$ & $\mathbf{- 0 . 1 2 3}$ & $\mathbf{0 . 6 3 0}$ \\
$k_{1}$ & -0.005 & -0.001 & 0.016 & 0.000 & $\mathbf{0 . 2 8 8}$ & $\mathbf{0 . 8 9 7}$ & -0.070 & -0.002 & 0.096 & 0.000 & $\mathbf{0 . 3 6 7}$ & $\mathbf{0 . 8 6 4}$ \\
$k_{2}$ & -0.157 & 0.003 & -0.179 & 0.000 & 0.017 & $\mathbf{- 0 . 0 0 5}$ & -0.606 & 0.014 & -0.143 & 0.001 & 0.024 & $\mathbf{0 . 0 7 0}$ \\
$t_{0}$ & -0.008 & -0.007 & 0.160 & 0.001 & 0.000 & 0.007 & -0.146 & -0.034 & 0.862 & 0.003 & 0.002 & 0.033 \\
\hline
\end{tabular}

